\title{
The collapse of credit booms: A competing risks analysis*
}

\author{
Vítor Castro* \\ Loughborough University and NIPE \\ Rodrigo Martins ^ \\ University of Coimbra and CeBER
}

\begin{abstract}
This paper analyses the collapse of credit booms by using a discrete-time competing risks duration model over a panel of 67 countries for the period 1975q1-2016q4 to disentangle the factors behind the length of benign and harmful credit booms. The results show that economic growth and monetary authorities play the major role in explaining the differences in the length and outcome of credit booms. While more growth contributes to longer booms that are more likely to land softly, higher interest rates and central bank independence cut credit booms short but make hard landings more likely. Moreover, we found that the longer a credit boom lasts the more likely it is to end in a systemic banking crisis. Although both types of credit expansions have an increasing probability of ending, as they grow older - exhibiting positive duration dependence - hard landing credit booms have proven to be statistically longer.
\end{abstract}

Keywords: Credit booms; Duration analysis; Competing risks model; Multinomial logit;

Central Bank independence.

JEL Classification: C25, C41, E51.

\footnotetext{
${ }^{*}$ We acknowledge the editor and two anonymous referees for their useful comments and suggestions.

* School of Business and Economics, Loughborough University, Loughborough, Leicestershire LE11 3TU, UK. Economic Policies Research Unit (NIPE), University of Minho, Campus of Gualtar, 4710-057 Braga, Portugal. Tel.: +44(0) 1509 222706; E-mail: v.m.q.castro@,lboro.ac.uk

^ Faculty of Economics, University of Coimbra, Av. Dias da Silva 165, 3004-512 Coimbra, Portugal. Centre for Business and Economics Research (CeBER), Av. Dias da Silva 165, 3004-512 Coimbra, Portugal. Tel.: +351239790543; E-mail: rodrigom@fe.uc.pt
} 


\section{Introduction}

Credit has always been regarded by the economic theory as important to support investment and ultimately economic growth. However, when credit grows too fast, financing ends up being extended to riskier investment projects with inferior net present value, fraudulent behaviour is more likely to occur and the overall quality of the projects that are backed up drops. This means that in the aftermath of credit expansions the banking sector may experience significant vulnerabilities that eventually can trigger systemic banking crises. According to our data, approximately 1 out of 4 credit booms end up this way. The recent global financial crisis originated in part by a swift increase of mortgage loans in the United States - is one example of this scenario and has contributed to the belief that credit booms should be monitored carefully and their dynamics better understood (Reinhart and Rogoff, 2009; Baron and Xiong, 2017).

This has been an important topic of investigation in recent years and several determinants of credit booms have been identified. ${ }^{1}$ However, our understanding of why some credit expansions end up badly while others land smoothly remains incomplete. Researchers have found it to be particularly difficult to grasp empirically. In reality, larger magnitudes and longer durations have been the only consistent identifiers of harmful credit booms found in the literature (Gourinchas et al., 2001; Barajas, et al., 2009; Arena et al., 2015; Dell'Ariccia et al., 2016; Meng and Gonzalez, 2017). Nonetheless, so far no work has provided sophisticated statistical proofs for these claims or explanations to why some last longer than others. In light of what we know from the literature, understanding the duration of lending growth episodes, the mechanism behind their formation and the type of behaviour they exhibit over time is of crucial importance to comprehend the impact of credit booms on the financial and banking sectors and also for the implementation of adequate policy measures. This remains a research challenge that the present study intends to undertake.

This paper employs a discrete-time competing risks model to analyse the duration and outcome of credit booms making use of an extensive quarterly dataset covering 67 countries from $1975 q 1$ to $2016 q 4$. This relies on a framework in which the hazard rate is the sum of two

\footnotetext{
${ }^{1}$ See Gourinchas et al. (2001), Sidaoui et al. (2011), Borio and Disyatat (2011), Mendoza and Terrones (2008, 2012), Calderón and Kubota (2012); Gourinchas and Obstfeld (2012), Elekdag and Wu (2013), Arena et al. (2015), Dell'Ariccia et al. (2016), Meng and Gonzales (2017), Avdjiev et al. (2018), Castro and Martins (2019).
} 
conditional probabilities involved in the overall credit expansion process: the probability of ending softly and the probability of ending in a systemic banking crisis. This approach is novel to the analysis of credit expansions and portrays more adequately the reality of the phenomenon.

This paper confirms statistically that the probability of credit booms ending increases over time at a decreasing rate and that no significant difference exists in the speed they exhibit when collapsing into different outcomes. It further shows that economic growth is important to explain not only differences in the duration of any kind of credit boom but also differences in length between harmful and innocuous ones. Additionally, Central Bank independence and monetary policy are also found to be relevant predictors of their duration.

The rest of the paper is organized as follows. Section 2 reviews the relevant literature on credit booms and on their outcomes. Section 3 describes the empirical methodology and data. The empirical analysis and the discussion of the results are presented in Section 4. Finally, Section 5 concludes.

\section{Contextual framework}

The literature on credit booms has noticeably expanded since the turn of the decade. Although some recent theoretical efforts have been made to understand the phenomenon (see, for instance, Boissay et al., 2016 and Burnside et al., 2016), the bulk of research still resides in empirical applications that emphasize the role played by macroeconomic variables. First, credit expansions have been consistently linked to sharp increases in capital inflows that raise the supply of loanable funds, usually occurring in periods of disinflation or/and low interest rates in developed economies. (Gourinchas et al., 2001; Calderón and Kubota, 2012; Gourinchas and Obstfeld, 2012). Second, they are also associated with a higher ratio of private credit to bank deposits which, additionally, is seen to increase financial fragility (Borio and Disyatat, 2011; Gourinchas and Obstfeld, 2012). In particular, Sidaoui et al., (2011) report that rising inflows of foreign capital may lead to excessive monetary and credit expansions, which according to Avdjiev et al. (2018) can be exacerbated if the share of external bank lending is high. Third, productivity shocks are also reported to increase the credit-to-GDP ratio via pressuring the capital stock to increase at a higher rate than GDP. Overall, healthier economies are more likely 
to exhibit credit expansions (Mendoza and Terrones, 2008, 2012; Meng and Gonzales, 2017). Fourth, financial reforms and broad domestic differences are also highlighted, particularly reforms associated with financial liberalization, domestic expansionary monetary and fiscal policies, less flexible exchange rate regimes and frailties in the supervision of the banking system are all found to increase the occurrence of credit booms (Mendoza and Terrones 2012; Elekdag and Wu 2013; Arena et al., 2015; Dell'Ariccia et al., 2016). More recently, Castro and Martins (2019) extend the analysis of credit booms to the role of the political environment and find that credit booms are less likely when right-wing parties are in office, especially in developing countries, and when there is political instability. They also show that Central Bank independence reduces the probability of credit booms.

This paper, besides exploring the multiple economic determinants of credit booms discussed in the literature, borrows from Castro and Martins (2019) and also investigates the importance of government stability and Central Bank independence (CBI) on the duration and outcomes of credit booms. A higher degree of government stability - like the government's ability to carry out its programme or to stay in office - can lead to a more stable economic environment, thus favouring longer credit surges. The relevance of Central Banks to explain credit patterns is undisputed as well as the important role they play in monitoring the financial system and in preventing markets - and the overall economy - from overheating. However, political pressures exerted by governments can constrain the work of Central Banks, reducing their desired independence. ${ }^{2}$ From the governments' perspective, a credit expansion is definitively a good thing. More investment and higher consumption makes voters happier, and happier voters tend to improve the incumbents' re-election chances. Hence, it is reasonable to assume that governments are particularly fond of periods of abnormal credit growth, and dislike dealing with credit crunches. Furthermore, they are also aware that Central Banks play a major role in credit booms' dynamics. As such, it is expected that less independent Central Banks may help increase the occurrence, intensity and length of credit booms; moreover, they are also expected to be less predisposed to intervene when the economy displays strong signs of overinvestment, excessive risk and/or overinflated market bubbles.

\footnotetext{
${ }^{2}$ See Chappell et al. (1993); Havrilesky, (1988, 1991) and Lohmann, (1998).
} 
Understanding why some credit booms end up by seriously disrupting the banking system and the overall economy is of critical importance. Despite some advances that have been made in this field, findings tend to be mixed and significant differences between good and bad credit expansions have been hard to capture. For instance, Gourinchas et al. (2001) report no relevant differences in key macroeconomic variables between both types of expansions. However, more recent works do find some dissimilarities. Dell'Ariccia et al. (2016) point out that starting at a higher level of financial depth increases the likelihood of having a harmful boom, while Arena et al. (2015) found that macroeconomic fluctuations seem to be larger and exhibit more sudden declines when credit booms result in banking crisis. Meng and Gonzalez (2017) report that this is also the case when the size of the financial sector grows, especially above macroeconomic consistent levels. ${ }^{3}$ Of particular importance to this paper is fact that most studies seem to systematically report that harmful credit booms are associated with larger magnitudes and longer durations. This suggests that to understand what affects the length of credit booms is fundamental to further improve our knowledge about why some end up creating havoc and others do not. This paper tries to fill this gap in the literature by relying on adequate duration analysis techniques, which are presented in the next section.

\section{Econometric Methodology and Data}

The duration of credit booms is modelled by specifying the conditional probability of leaving that spell, i.e. the hazard rate. In this case, the hazard rate can be seen as the sum of two conditional probabilities: the probability of a credit boom ending softly and the probability of it ending into (or being followed by) a systemic banking crisis. In this context, the econometric model for multiple outcomes in a discrete-time framework, i.e. the multinomial logit model (Allison, 1982; Jenkins, 2005), ${ }^{4}$ can be more appropriate than single-risk duration models. ${ }^{5}$

\footnotetext{
${ }^{3}$ However, they do not find any association between "bad" credit booms and macroeconomic and financial policies - exception made to the quality of regulations and supervision of the banking system.

4 This discrete-time version has the important advantage of allowing for a straightforward inclusion of time-varying co-variates. Moreover, Allison (1982) argues that when the time units are large, a discrete-time duration analysis may be more effective than its continuous-time counterpart. It is the case in this study where the data are grouped into large (quarterly) discrete-time intervals.

${ }^{5}$ Given that not all credit booms end softly - in our data we observe that about one in four credit booms ends hardly in a banking crisis - the estimation of a single risk duration model may lead to a potential bias, as it restricts the estimated coefficients to be the same when potential outcomes can differ.
} 
We observe whether credit booms end in a banking crisis or not within one-quarter time intervals. This implies that the length - or duration - of a specific credit boom is a discrete-time random variable $T$ (Allison, 1982). Moreover, in each period, the credit boom can be ongoing, end softly or hardly. These potential outcomes are recorded as 0,1 or 2 , respectively. The hazard function $(h(t))$ will then measure the probability of a credit boom (in given country) ending at time $t$, conditional on being in that state until that moment. As credit booms can end differently, the duration variable must be associated with two outcomes, namely: $T_{S L}$, i.e. the duration of credit booms that end softly (soft landing); and $T_{H L}$, i.e. the duration of credit booms that end in, or are followed by, a banking crisis (hard landing). Assuming that the discrete-time hazard function can be specified as a multinomial logistic function, then the multinomial logit model can be seen as a proportional odds (hazards) model in a competing risks framework (Jenkins, 2005). ${ }^{6}$ In this context, the hazard function is defined as:

$$
h_{m}(t)=\frac{\exp \left[Z_{m}(t)\right]}{\sum_{j=0}^{2} \exp \left[Z_{j}(t)\right]}
$$

where $h_{m}(t)$ is the hazard for exit into state $m$, which takes the value of 0 (ongoing credit boom), 1 (soft landing) and 2 (hard landing), and $Z_{m}(t)$ is a function that captures the effect of time-varying regressors and, additionally, it can also account for the presence of duration dependence. The probability of a transition into state $m$ at time $t, P_{m}(t)$, can then be expressed as the product of the probability of survival until time $t$ and the conditional probability of exiting to state $m$ at time $t$, that is:

$$
P_{m}(t)=h_{m}(t) S(t)=\frac{\exp \left[Z_{m}(t)\right]}{\sum_{j=0}^{2} \exp \left[Z_{j}(t)\right]} S(t), \quad m=0,1,2
$$

Let us define $Z_{m}(t)=\boldsymbol{\beta}^{m} \boldsymbol{x}_{t}+\gamma^{m} \operatorname{LnDurCBoom}_{t}$, where $\boldsymbol{x}_{t}$ denotes the vector of explanatory variables at time $t$, and $\boldsymbol{\beta}^{m}$ is the vector of corresponding parameters to estimate regarding both outcomes at the end of a credit boom, $\operatorname{LnDurCBoom}_{t}$ measures the logarithm of the duration of a credit boom at time $t$, and $\gamma^{m}$ is the parameter that accounts for duration

\footnotetext{
${ }^{6}$ Competing risks are said to be present when a credit boom is at risk of more than one mutually exclusive outcome, such as, in this case, it ending softly or badly. Hence, the occurrence of one of these outcomes will prevent the other from happening and the probability of each competing outcome is somehow regulated by the other competing outcome. This competing risks analysis over the events of credit booms represents one of the main novelties and an important contribution of this paper.
} 
dependence, i.e. whether the likelihood of a credit boom ending softly or hardly in a given moment in time increases $(\gamma>0)$ or decreases $(\gamma<0)$ over its duration.

Considering ongoing credit booms as the base outcome (and normalizing the respective coefficients to zero, as is standard in the multinomial logit model), the specific "destination" hazard function can be written as:

$$
h_{m}\left(t \mid \boldsymbol{x}_{t}\right)=\frac{\exp \left[\boldsymbol{\beta}^{m} \boldsymbol{x}_{t}+\gamma^{m} \text { LnDurCBoom }_{t}\right]}{1+\sum_{j=1}^{2} \exp \left[\boldsymbol{\beta}^{j} \boldsymbol{x}_{t}+\gamma^{j} \text { LnDurCBoom }_{t}\right]} S(t), \quad m=1,2
$$

Hence, the likelihood contribution of a credit boom spell is

$$
\begin{aligned}
& L(\boldsymbol{\beta}, \gamma \mid \boldsymbol{x}, \text { LnDurConsol })= \\
& \quad=\prod_{k=1}^{t} \frac{\exp \left[\left(\boldsymbol{\beta}^{1} \boldsymbol{x}_{k}+\gamma^{1} \text { LnDurBoom }_{k}\right) c_{k}^{1}+\left(\boldsymbol{\beta}^{2} \boldsymbol{x}_{k}+\gamma^{2} \text { LnDurCBoom }_{k}\right) c_{k}^{2}\right]}{1+\sum_{j=1}^{2} \exp \left[\boldsymbol{\beta}^{j} \boldsymbol{x}_{k}+\gamma^{j} \text { LnDurCBoom }_{k}\right]}
\end{aligned}
$$

where $c_{k}^{1}$ and $c_{k}^{2}$ are indicators for the transition to each of the two possible destinations (outcomes), namely: soft landing $(m=1)$ or hard landing $(m=2)$ credit booms at time $k$. As it is common in duration models, credit booms that are still ongoing at the end of the observation period $t$ are treated as right-censored observations.

The likelihood contribution for an individual with spell length $k$ is specified as:

$$
L(\boldsymbol{\beta}, \gamma \mid \boldsymbol{x}, \operatorname{LnDurCBoom}, p)=\sum_{s=1}^{2} L\left(\boldsymbol{\beta}, \gamma \mid \boldsymbol{x}_{s}, \operatorname{LnDurCBoom}_{s}\right) p_{s}
$$

where $p$ is the associated probability and $s$ is the number of location points. As shown by Allison (1982) and Jenkins (2005), this is similar to the likelihood of a multinomial logit model where the dependent variable - here labelled as CreditBoom_id - takes the value of: 0, for ongoing credit booms; 1, for those that end softly; and 2, for those that end hardly. LnDurCBoom measures the respective log duration at time $t$.

This model is estimated over a panel of 67 countries for the period 1975q1-2016q4. ${ }^{7}$ Credit booms are identified according to the works of Gourinchas et al. (2001) and Barajas et al. (2009). A credit boom (CreditBoom) is defined as an episode where the deviation of the ratio of credit to GDP from its trend exceeds 1.5 times of its standard deviation or the (year-on-year) growth in the credit-to-GDP ratio exceeds 20 percent. ${ }^{8}$ Based on the identification strategy used

\footnotetext{
${ }^{7}$ The list of the countries used in our study, start and end dates and duration of credit booms are shown in Table A1 in Appendix. We also provide there information about the credit boom outcomes (soft versus hard landing).

${ }^{8}$ In some robustness checks, we also consider alternative definitions where the threshold is set at 1.75 and 2.0 times the standard deviation, respectively.
} 
by Barajas et al. (2009), hard landings are then defined as credit booms that are followed by a systemic banking crisis either immediately or within eight quarters of their final period. The other credit booms are considered soft landings. The episodes of systemic banking crises were obtained from Laeven and Valencia $(2008,2010,2012)$ and updated for the more recent years following their procedure.

We identify 220 credit boom spells, 165 of which ended softly while the other 55 ended or were followed by banking crises (see Table A2 in Appendix). They vary in length between one and 32 quarters, but, on average, credit booms that end up in banking crises last 10.6 quarters, while the others last around 7.2 quarters. Whether this difference is statistically significant or not is an issue that we will address in the empirical analysis. However, before moving on to that analysis it is worth to have a look at Figure 1, where the histograms and survival functions for the duration of credit booms (all, soft and hard landing) are presented. The most frequent episodes of credit booms last between 2 and 10 quarters. A similar pattern is found for those that end softly, while hard landings are most frequent for credit booms lasting between 5 and 9 quarters (but with a few lasting much longer). Hence, the picture is not clear on whether the former have a higher propensity to last longer than the latter or not. Moreover, the probability of credit booms surviving, after a certain duration, substantially decreases over time regardless of their ultimate outcome. A visual inspection does not clarify which one is faster, as such the next section tests for the presence of duration dependence and assesses whether their dynamics is different or not.

\section{[Insert Figure 1 around here]}

Although one of the goals of this paper is to identify differences in the duration dependence dynamics of credit booms regarding two possible exiting states, another goal is to assess whether and how the economic environment, central bank behaviour, government stability and financial uncertainty affect the likelihood of credit booms ending softly or hardly. These determinants are discussed in detail next.

To account for the effect of the economic environment, we rely on a set of economic variables commonly found in the related literature (Gourinchas et al., 2001; Borio and Disyatat 2011; Calderón and Kubota, 2012; Gourinchas and Obstfeld, 2012; Mendoza and Terrones, 
2008, 2012; Meng and Gonzales, 2017): total gross capital inflows as percentage of GDP (CapInflows) as proxy for capital inflows; the ratio of private credit to bank deposits (CredDeposits) as a proxy for the liquidity in the banking system; growth rate of real GDP (RealGDPgr); trade openness (Openness) measured by exports plus imports over GDP; exchange rate flexibility (ExchRateFlex), proxied by the coarse classification of the exchange rate regime developed by Reinhart and Rogoff (2004), and updated by Ilzetzky, et. al. (2009) and similar sources mentioned in that paper for more recent years. We expect that better economic conditions may fuel longer credit booms; whether their outcome is good or bad, it is open to the empirical discussion provided in the next section. ${ }^{9}$

The role of monetary authorities in the credit booms dynamics is controlled for using: the Central Bank interest rate (CBrate), which can not only affect the quantity but the quality of credit; and an index for its degree of independence (CBindep), measured by the CukiermanWebb-Neyapti weighted index and updated by Garriga (2016). Monetary policy is an important factor to consider, as Central Banks are the main regulators of the quantity of money present in the system. During credit expansions, they may exhibit a loose monetary policy of low interest rates, which makes it easier for economic agents to obtain credit, fuelling its growth above normal levels or its fundamentals. This may also promote longer booms of credit and the buildup of conditions for them to end in a banking crisis. Monetary authorities also play an important role in monitoring the financial system and in preventing markets - and the overall economy from overheating and collapsing into a crisis. We expect this role to be fulfilled more efficiently when they are more independent. This means that we expect credit booms to be shorter and land softly when the degree of Central Bank independence is higher.

To account for the role of government stability and financial (and economic) uncertainty on the credit booms dynamics we use, respectively, the government stability index from the

\footnotetext{
${ }^{9}$ Due to data availability we leave out from our analyses one important aspect, namely that credit booms and the associated macro business cycles also relate to the financial conditions of banks at the micro level. In particular, the financial health and profitability of banks are probably relevant to understand why a credit boom ends in a systemic banking crisis. Dell' Ariccia and Marquez's (2006) argue that the lowering of lending standards typically registered in a boom comes at the cost of having more risky clients, leading to a subsequent reduction of bank's assets quality. Moreover, banks should yield higher profits in the expanding phase of credit booms but experience a collapse in their earnings in the ending phase of the boom (see Drehman et al. 2011). Therefore, the possible appearance of a systemic crisis, when the bubble burst, may relate to how low-quality bank assets actually are at the time, and how strong the profit reduction is.
} 
International Country Risk Guide, which measures which measures the government's ability to carry out its program and to stay in office, and the VXO volatility index of Chicago Board Options Exchange S\&P 100. Instability and uncertainty are conditions that may lead to shorter booms of credit which may end up badly.

\section{Empirical Analysis}

The results and findings from the empirical analysis are presented and discussed in this section. First, we present a basic duration analysis with a standard Weibull specification to check for the presence of duration dependence in the duration of credit booms simply splitting them by outcome. Then, we proceed with the competing risks analysis where the outcome of each credit boom is properly taken into account in the structure of the duration model. Finally, some robustness checks are provided.

\subsection{Basic duration analysis}

In our first exploratory analysis, we focus on checking for the presence of duration dependence, i.e. whether the likelihood of an event ending over its life is dependent on its duration or not. Relying on a proportional hazard continuous-time framework and a Weibull specification, the shape of the hazard function can be made dependent on a duration parameter and some time-invariant covariates: ${ }^{10}$

$$
h(t, \boldsymbol{x})=\pi t^{\pi-1} \exp \left(\boldsymbol{\beta}^{\prime} \mathbf{x}\right)
$$

where $\pi$ is a non-negative parameter providing information about the nature of duration dependence. A value of $\pi$ greater (lower) than 1 indicates the presence of positive (negative) duration dependence. If $\pi$ is equal to one, there is no duration dependence; $\boldsymbol{\beta}$ is a $(k+1) \times 1$ vector of parameters to be estimated and $\mathbf{x}$ is a vector of $k$ time-invariant covariates plus the usual element 1 for the constant term.

The empirical results from the estimation of the continuous-time Weibull model for the duration of credit booms are reported in columns 1-6 in Table 1. A basic and an augmented

\footnotetext{
${ }^{10}$ For details on this model and how it is estimated by maximum likelihood, see Jenkins (2005), Castro (2010), Castro and Martins (2013) and Agnello et al. (2015, 2018).
} 
version of the model, with some time-invariant covariates, are regressed for credit booms treated indifferently (Any Boom) and as ending softly (Soft) or hardly (Hard), i.e. in a banking crisis. According to Allison (2014), methods for single kinds of events can be applied separately to each kind of event as follows: when analysing one kind of event - soft (hard) credit boom, in our case - the other kind of event - hard (soft) credit boom - is treated as censored at its occurrence. For each regression - apart from the estimated coefficients and the corresponding robust standard errors clustered by country - we report the number of observations, countries, complete spells (i.e. not censored, that ended in the sample period), the value of the loglikelihood function ( $\log L)$, the Schwarz Bayesian Information Criterion (SBIC) and the McFadden's pseudo- $\mathrm{R}^{2}$.

\section{[Insert Table 1 around here]}

A one-sided test is used to detect the presence of positive duration dependence (i.e., whether $\pi>1$ ) and the sign "+" indicates the respective significance at a $5 \%$ level. The results corroborate this hypothesis not only for credit booms assessed indifferently, but also for each of the respective outcomes/kinds, which means that the likelihood of a credit boom ending, no matter the outcome, increases as the time goes by. ${ }^{11}$ Moreover, $\pi$ has also proven to be significantly lower than 2 , which implies the presence of decreasing positive duration dependence. ${ }^{12}$ This means that the probability of credit booms ending at time $t$, given that they lasted until that moment, increases over time at a decreasing rate. Soft credit booms behave in the same way, however the likelihood of those that end hardly increases at a constant rate over their age. Despite the increase in the hazard is higher for hard than soft landing credit booms, a close inspection of the respective estimated hazard functions, shown in Figure 2.a), reveals that benign credit booms have a persistently higher rate of failure over their lives than those that end

\footnotetext{
11 More specifically, when the duration of a credit boom increases by one quarter, the hazard function, i.e. the probability of a credit boom ending at time $t$, given that it lasted until that moment, is expected to increase by 1.01 percentage point (p.p.). This effect is computed as follows: $d \widehat{h(t)} / d t=\hat{\pi}(\hat{\pi}-1) t^{\widehat{\pi}-2} e^{\widehat{\beta}_{0}}$, where $t$ is evaluated at its mean and $\hat{\beta}_{0}$.is the estimate for the constant term. For soft and hard landings the estimated increases in the hazard are 0.58 p.p. and 0.51 p.p., respectively. Alternatively, these results can be interpreted as elasticities since the logarithm of the hazard is a linear function of $\log t$ (see equation 6). Hence, a $1 \%$ increase in time since the moment a credit boom started is associated with a $0.509 \%(=\hat{\pi}-1)$ increase in the hazard of that boom ending. A similar interpretation can be done for soft and hard credit booms.

${ }^{12}$ For details on the speed of the duration dependence process, see Castro $(2010,2013)$.
} 
hardly. This implies that, on average, credit booms that end softly should be shorter than those that land in a financial crisis. ${ }^{13}$

\section{[Insert Figure 2 around here]}

When the model is augmented with time-invariant controllers we observe no significant difference either in the average duration of credit booms between developed and developing countries, but we do observe that they were shorter in the 1980s (with the exception of hard ones) and in the 2000s relatively to the second half of the 1970 s. ${ }^{14}$ These results are consistent with those of Arena et. al. (2015), However some relevant studies, like Drehman et al. (2011) and Borio et al. (2014), report an increase in the duration and magnitude of the average financial cycle over the past decades. We speculate that these contradictory results may relate to one, or some, of the following factors. First, our data starts only in the second half of the 1970s. This period is characterized by increases in public sector deficits, in an effort to offset the contractionary effects of the first jump in oil prices, and by waves of financial liberalization that extended to the early 1980 s, thus creating favourable conditions for lending. Second data differences, particularly regarding the number of countries and controllers used, may contribute to different conclusions. Finally, the statistical method we employ is different in the sense that only credit boom spells are considered in the discrete-time duration analysis.

Going beyond the analysis of the presence of duration dependence, we also assess the role of the economic environment, Central Bank independence, government stability and financial uncertainty. As the time units in which those variables are observed are large (quarters), it is more appropriate to use a discrete-time method (see Allison, 2014). Moreover, the inclusion of the above time-varying regressors is straightforward in such framework. Prentice and Gloeckler (1978) develop a discrete-time version of the proportional hazards duration model, which, extended with the discrete-time analogue to the continuous-time Weibull, yields the respective discrete-time hazard function: ${ }^{15}$

\footnotetext{
13 Following Jenkins (2005), we estimate their mean durations. In fact, credit booms that land softly have an estimated mean duration of 9.8 quarters against 17.6 quarters for those that land hardly.

${ }^{14}$ Note that their likelihood of ending increases over their duration, thus a higher propensity for shorter credit booms.

${ }^{15}$ For details on this discrete-time version and estimation procedure, see Jenkins (2005) and Castro (2010).
} 


$$
\begin{aligned}
P_{i t}=\operatorname{Pr}\left[T_{i}\right. & \left.=t \mid T_{i} \geq t, \mathbf{x}_{i t}\right]=1-\exp \left\{-\exp \left[(\pi-1) \ln t+\boldsymbol{\beta}^{\prime} \mathbf{x}_{i t}\right]\right\} \\
& \Leftrightarrow \ln \left[-\ln \left(1-P_{i t}\right)\right]=(\pi-1) \ln t+\boldsymbol{\beta}^{\prime} \mathbf{x}_{i t}
\end{aligned}
$$

where $t$ denotes the moment in which the value of each independent variable is observed and $\pi$ is the respective duration dependence parameter. This model is equivalent to the complementary $\log$-log (or Cloglog) function, where $\mathbf{x}_{i t}$ is a vector of time-varying explanatory variables.

The results from the discrete-time Cloglog model are reported in columns 7-9 in Table 1. The inclusion of other explanatory channels in the analysis of the duration of credit booms provides a richer and more complete understanding of its dynamics. Regarding the economic environment, while capital inflows (CapInflows) do not show any significant impact on the duration of credit booms, a rise in the credit-to-deposits ratio (CredDeposit) - i.e. the level of liquidity in the banking system decreases - leads to a reduction in the propensity for a credit boom ending, i.e. they are more prone to last over time. In fact, credit growing faster than deposits paves the way for longer booms. Surprisingly, this seems to be a more common trend in those that end softly, maybe because a higher credit-to-deposits ratio implies a smoother adjustment in the banking sector when the bubble bursts leading to a soft landing. As expected, credit booms also last longer when the economy is growing faster and this evidence is shared by both soft and hard landings: an increase in the GDP growth rate (RealGDPgr) has a significant negative impact on the likelihood of a credit boom ending over time. ${ }^{16}$

While the degree of openness of an economy (Openness) is irrelevant, a more flexible exchange rate regime (ExchRateFlex) prevents credit booms from lasting longer, especially the harmful ones. This result can be explained by unexpected exchange rate movements or contagion effects that may lead to an abrupt end of credit booms, which can have repercussions in the banking sector. Without time to adjust, banks can struggle with an increase of nonperforming loans due to unpredicted exchange rate movements and a banking crisis may arise.

The results also show that the length of harmful credit expansions is pushed back with more Central Bank independence (CBindep) and when the base interest rate (CBrate) is raised. It is reasonable to assume that the longer it takes for a bad credit boom to unfold the more

\footnotetext{
${ }^{16}$ However, it may also be promoted by that credit expansion. This endogeneity issue will be addressed in the robustness checks below.
} 
difficulties the banking system is expected to experience. As such, those variables that are found to help cut short these nefarious booms are probably smoothing their aftermath.

Additionally, financial uncertainty undermines the length of credit booms, especially benign ones. This might mean that changes in those indicators that are easily perceived by the banking sector - and allow them to easily adjust their behaviour - do not play a significant role in the curation of credit booms that harm the banking sector. However, changes in variables linked to contagion effects or unpredicted exchange rate movements and policy behaviour (monetary and political) may come as a surprise to the banking sector, leaving them no time to react and adjust their balance sheets, which can contribute to the genesis of a banking crisis.

Nevertheless, these controllers are not enough to explain the full duration dynamics. Despite their inclusion, positive duration dependence is still an issue. Moreover, when soft and hard credit booms are assessed separately, we even observe the presence of decreasing positive duration dependence for soft credit booms and constant for hard ones. However, looking at Figure 2.b) we conclude that soft credit booms have a consistently higher rate of failure over the length of their lives than those that end hardly. This confirms that despite the higher acceleration in the likelihood for hard credit booms to collapse over time, those that land softly remain more likely to end at any point in time than hard ones. Hence, as before and on average, the former are shorter than the latter.

\subsection{Competing risks analysis}

As credit booms can end up softly or in a banking crisis, the estimation of a single risk duration model can be biased, since - as stated before- it restricts the estimated coefficients to be the same when potential outcomes can differ. The simple procedure of splitting the analysis into soft and hard landing booms, randomly censoring the competing risk, does not solve the problem either, because we are still ignoring the interaction between the two possible outcomes and treating separately the common dynamics of credit booms before their outcome unveils. Allison (2014) also argues that this random censoring is non-informative as we have no control over when the other event occurs. For these reasons, a proper analysis of the process requires a model that accounts for a hazard rate that is the sum of two conditional probabilities: the 
probability of a credit boom ending softly and the probability of ending in a systemic banking crisis. Hence, the discrete-time competing risks model described in section 3 arises as a better alternative than a single-risk duration model for each outcome.

The empirical results from the analysis of the discrete-time competing risks multinomial logit model are presented in Table 2 . The estimated parameters inform us about the probability of a credit boom ending/landing softly $(S L)$ or hardly $(H L)$ relative to the probability that it continues over time, i.e. an ongoing credit boom $(O C B)$. In addition, we report the estimated coefficients for the contrast between $S L$ and $H L$ as a way of assessing the factors that drive the impact on the probability of a soft landing relative to a hard landing. This interaction between the outcomes is not possible to estimate with a single-risk duration model and examines the likelihood of a hard landing occurring as opposed to a soft landing.

For each estimation - besides allowing for different specifications to control for duration dependence (namely, the log duration, linear and time-dummies) - we report the same statistics at the bottom of the table as in Table 1. There we also report the suest-based Hausman and Small-Hsiao tests for the independence of irrelevant alternatives (IIA) assumption in order to assess whether the risks are independent or correlated. An important assumption of the multinomial logit model is that outcome categories have the property of IIA. This assumption requires that the inclusion or exclusion of categories does not affect the relative risks associated with the regressors in the remaining categories. Long and Freese (2014, pp. 407-411) argue that the multinomial logit model works best when the alternatives are dissimilar and not just substitutes for one another. ${ }^{17}$ As such, the respective tests for the IIA assumption (Long and Freese, 2014) are reported and show that the null of IIA is never rejected at a 5\% significance level (i.e. the odds of the outcome-J versus outcome-K are independent of the other alternatives). Hence, we can proceed with our analysis relying on the IIA assumption.

The first set of results (columns 1-3) corresponds to a specification where the degree of duration dependence is measured in a similar way to the discrete-time complementary-log-log

\footnotetext{
${ }^{17}$ For example, if the choices are taking a car, blue bus, or red bus to work; the two bus alternatives would be very similar and the IIA assumption would likely be violated. Therefore, for this reason (at least theoretically) the IIA assumption might make sense in our analysis as the risk of a credit boom ending softly might not be influenced by the risk of ending hardly or vice-versa as they are dissimilar alternatives in their essence.
} 
version of the Weibull model, with baseline hazard function given by $\alpha+(\pi-1) t$, where $t=$ LnDurCBoom (see Allison, 1982; Jenkins 2005; and Agnello et al., 2013). This means that testing for positive (negative) duration dependence in this competing risks model corresponds to test whether $\gamma=\pi-1$ is statistically higher (lower) than zero. More specifically, when $\gamma>0$ $(\gamma<0)$ the likelihood of a credit boom ending softly or hardly in a given moment in time increases (decreases) as the time goes by, i.e. as the boom gets older.

\section{[Insert Table 2 around here]}

The empirical evidence provided by this model confirms that both types of credit expansions display positive duration dependence (see columns 1 and 2). Most importantly, the results also show that, as time goes by, the probability of a boom ending in a banking crisis increases relatively to the likelihood of ending softly (see column 3). Hence, the competing risks model helps us to directly test the question raised in section 3 - and the graphical evidence provided in section 4.1 - and to statistically prove that credit booms that end up hardly are more prone to last longer than benign ones. This evidence and the indication that credit booms are, in general, duration dependent are further corroborated by a simple linear specification of time (DurCBoom) (see columns 4-6). Also, columns 7-9 provide similar results based on a more flexible time-dummies approach that imposes no constraints on the shape of the hazard function but adds instead a dummy variable for each year that an event is reported. ${ }^{18}$

The duration aspect alone is not enough to access the nature of a credit expansion. However, our results suggest that it may serve as a relevant early warning indicator. We believe that it is not time by itself that causes credit booms to end badly, but what happens as time elapses. Typically, banks' vulnerabilities tend to intensify as credit expansions progress and also as the economy becomes increasingly "hotter". We speculate that the time it takes to reach the point where economic systems are strongly compromised, in most cases, is relatively long, which can help explain why bad booms exhibit longer durations. As such, the economic adjustment process that follows the collapse of a credit boom may prove to be more or less difficult because of differences in length. One way of looking at the relevance of duration, is

\footnotetext{
${ }^{18}$ Respectively $D_{-}$Dur $y r l$ to $D_{-}$Dur $y r 4$, where the base category corresponds to spells longer than four years because we cannot simultaneously observe soft and hard landing credit boom spells of longer duration - see Figure 1.
} 
that it seems to synthesize economic agents' persistence in some behaviours that are simply unsustainable in the long-run.

Regarding the additional conditionings, the empirical findings provide a more fine-tuned perspective on the role they play in the dynamics of credit booms. While the previous duration analysis suggests that capital inflows do not affect the likelihood of a credit boom ending, the competing risks approach reveals that capital inflows do play an important role: as capital inflows increase, the probability of a hard landing grows relative to a soft landing. ${ }^{19}$ In fact, rising inflows of foreign capital may intensify the vulnerabilities associated with currency and maturity mismatches (Akyuz, 2009) and create distortions in asset prices (Agnello and Sousa, 2013; Agnello et al., 2012) that may lead to a banking crisis. This implies that policy measures aimed at reducing the inflow of capitals when a credit boom is building up can mitigate the predisposition for a hard landing.

The propensity for harmless credit booms is also consistently reduced by an increase in the credit-to-deposits ratio, which means they tend to be longer, as previously observed in the single-risk duration analysis (see Table 1). Additionally, economic growth remains crucial in promoting longer credit booms whatever their nature is. In particular, a one p.p. increase in the GDP growth rate leads to an expected change of the odds for the contrast soft (hard) versus ongoing credit boom by a factor of $\exp \{-0.174\}=0.84(\exp \{-0.342\}=0.71)$, i.e. to a decrease of about 16\% (29\%) in that contrast/odds-ratio (see columns 1 and 2). In fact, stronger economic growth should contribute to create sounder conditions for a sustainable growth of credit (Mendoza and Terrones, 2008, 2012; Meng and Gonzales, 2017) as such credit expansions, driven by fast growing economies, have a tendency to thrive. Additionally, our results show that hard landings are less likely than soft ones when growth is higher. Their odds-ratio is estimated to decrease by around 15\% when GDP growth rises by one p.p. Overall, this means that

\footnotetext{
${ }^{19}$ A more intuitive interpretation can be given using an odds-ratios analysis instead. In the multinomial logit model, the exponential of a coefficient corresponds to the relative risk ratio (of a category relatively to the base category) or odds-ratio for a unit change in the corresponding variable (for details, see Long, 1997). Therefore, we observe that when the total gross capital inflows as percentage of GDP increase by one p.p., the odds-ratio of a credit boom ending hardly relatively to ending softly varies by a factor of $\exp \{0.272\}=1.31$, ceteris paribus (model with LnDurCBoom). This means an increase of around $31 \%$ in the respective ratio, meaning that hard landings are more prone to occur as capital inflows increase.
} 
economic growth fuels the length of a credit expansion, but in the case of the bubble bursting this better performance helps to accommodate any collateral damages leading to a soft landing.

The competing risks approach also confirms that the degree of openness does not seem to matter. But a marginal positive impact of the exchange rate flexibility on the likelihood of soft and hard landings is reported, but no significant differences are found between them.

Regarding the role of the monetary authorities, we observe that hard landings are significantly more likely to occur, rather than a credit boom surviving, when the monetary authority increases the interest rate and in countries exhibiting more independent central banks. These results are similar to the ones obtained in the previous sub-section, however, when the outcomes are compared, some interesting findings are recorded: credit expansions are more likely to end in a banking crisis rather than landing softly when the interest rate is increased and the central bank enjoys of more independence. More independent central banks have clear mandates to pursue a policy of low inflation rate, which in a scenario of a credit boom will not be easy to achieve without interest rate increases. These may indeed put an end to a credit boom and inflationary pressures more quickly, but at the expense of the build-up of more nonperforming debt which can put the banking sector at risk.

What these findings seem to be telling us is that while high interest rates and more Central Bank independence are cutting short (bad) credit booms, thus presumably reducing their nefarious consequences, ${ }^{20}$ they are actually contributing to make hard landings more likely. This means that a more independent central bank is more likely to end a credit boom that could potentially result in a systemic banking crisis. This may create the impression that having more independence is not desirable from a policy perspective. On the contrary, the short-term costs associated with this feature of the monetary authority may be smaller than the long-term benefits of preventing a larger (and more costly) systemic banking crisis in the future. Moreover, as hard landings are less likely when the economy is growing faster - as discussed above - maybe monetary authorities should take advantage of that timing to cut short potentially harmful credit bubbles.

\footnotetext{
${ }^{20}$ This result is partially in line with the findings provided by Castro and Martins (2019), in the sense that if credit booms tend to be cut shorter under more independent monetary authorities, they will also be less likely to occur when that independence prevails.
} 
As to the role played by government stability, the evidence is weak but the results seem to suggest that hard landings are more likely to occur when the government's ability to carry out its programme and to stay in office is improved. On the contrary, the effect of financial uncertainty is highly significant for those credit booms that end softly. Financial volatility acts as a warning mechanism for the banking sector, which seems to give a clear incentive for them to adjust their balance sheets, leading a credit boom to a quicker but safe end. Finally, no significant differences are observed between developed and developing/emerging countries in any of the contrasts considered.

\subsection{Robustness Checks}

In this section, we provide some robustness checks of our results vis-à-vis two major econometric experiments. We start by tackling potential endogeneity problems and afterwards we consider alternative definitions of credit booms.

Even though we use lags of the independent variables to account for potential simultaneity (and delays in data reporting), we also further address the issue of endogeneity by employing an instrumental variables (IV) approach. A summary of the empirical findings is reported in the columns 1-3 of Table 3 . In the first step, three potentially endogenous variables i.e. CapInflows, CredDeposit and RealGDPgr - are instrumented with their first to fourth lags and the first stage OLS estimations show that the instruments are not weak. ${ }^{21}$ In the second-step, we use the fitted values of the above mentioned potentially endogenous regressors in the estimation of the multinomial logit model. However, the Durbin-Wu-Hausman test does not reject the exogeneity hypothesis at the same level of significance. Nevertheless, the main findings and conclusions of our study remain unchanged, confirming the important role played by duration dependence, economic growth, monetary authorities and uncertainty.

\section{[Insert Table 3 around here]}

As an additional robustness check, we re-estimate all model specifications using two alternative, more restrictive criteria for the identification of credit booms, where the threshold in

\footnotetext{
${ }^{21}$ In fact, the results from both the Cragg-Donald and Kleibergen-Paap F-statistic indicate that we can reject that they are weak at a 5\% significance level. The respective critical value comes from Stock and Yogo's (2005) weak identification test for a 5\% maximal IV relative bias.
} 
the Gourinchas et al. (2001) and Barajas et al. (2009) criteria used in this study is now set at 1.75 and 2.0, respectively. The results are reported in columns 4-9 in Table 3. Besides some stronger evidence for the role of government stability in the dynamics between the outcomes of credit booms, favouring hard landings, the main empirical findings remain both quantitatively and qualitatively very similar to those of the baseline model specifications.

Finally, we split the sample into developed and developing/emerging countries to account for possible heterogeneity not captured by the dummy Developed. While capital inflows, central bank independence and uncertainty drive the risk of hard landing credit booms in developed countries, central bank interest rate and government stability enhances the risk of hard landing credit booms in developing countries. Moreover, economic growth promotes longer credit booms in developing countries, no matter its outcome, but hard landing credit booms are less likely than soft ones in developing emerging countries when the economy is growing faster.

These separate results must be analysed with a pinch of salt, as the reduction in the number of spells in a framework with three possible outcomes may lead to an overestimation of the standard errors, which undermines the statistical significance of the respective coefficients. ${ }^{22}$

\section{[Insert Table 4 around here]}

\section{Conclusions}

This paper addresses one uncharted area in the literature related to what determines the length of credit booms. It further improves the understanding of this subject by taking into account the common dynamics of credit booms before their outcome unveils. A discrete-time competing risks duration model - more precisely, a multinomial logit model - is employed to estimate the differences in the dynamics behind those booms that end without collateral damages and those that result in a systemic banking crisis. Our main findings have proved to be

\footnotetext{
${ }^{22}$ To check whether outliers might be driving some of the results, we re-estimated the model excluding those events that last more than 25 quarters and some low-income countries for which the quality of the data might be considered dubious. The results from those experiments were very similar to the ones reported in the paper. To keep the analysis parsimonious, those results are not reported here but they are available upon request.
} 
robust to different specifications of the baseline hazard function, the presence of endogeneity, and alternative definitions of credit boom episodes.

The results confirm that both types of credit booms display strong evidence of positive duration dependence, i.e. both are more likely to end as they grow older, but credit booms that are followed by banking crisis have shown to be longer than those that land softly. One important implication of this result is that as credit booms prevail in time, they create imbalances in the economy that are hard to stabilize when the credit boom bubble bursts. We believe that the importance of duration for the aftermath of credit expansions relies on the behaviour of economic agents. Typically, Banks' vulnerabilities tend to intensify as credit expansions progress and also as the economy becomes increasingly "hotter". As such, the economic adjustment process that follows the collapse of any credit boom may prove to be more or less difficult because of differences in length.

We also find strong evidence that economic growth plays a major role in explaining the differences in length and outcome of credit booms, promoting longer credit booms whatever their nature. Although longer durations increase the risk of a boom ending up in a banking crisis, a harmful ending is less likely to occur than a soft one when growth is higher.

The role played by the monetary authorities also seems to be relevant as the hazard duration of harmful credit booms increases with more Central Bank independence and higher interest rates. Still, in this context, booms are more likely to end up in a banking crisis than in a soft landing. What these findings seem to be telling us is that while high interest rates and more independent monetary authorities are cutting short bad credit booms - presumably as an attempt of reducing their nefarious consequences - they are also contributing to their arrival. As such, more independence and the policy of high interest rates seems to be a question of trading more frequent banking crisis for less violent ones.

Our results also show that an increase in the credit-to-deposits ratio improves the longevity of credit expansions. This is especially true for benign ones that also benefit from less financial uncertainty. Financial volatility seems to be acting as a warning mechanism for the banking sector, which may incentive them to adjust their balance sheets, leading a credit boom to a quicker but harmless end. However, capital inflows are found to boost the propensity for a 
hard landing relatively to a soft one. This implies that measures aimed at reducing the inflow of capitals when a credit boom is building up can mitigate the risk of a banking crisis when the credit bubble bursts. While the degree of openness does not seem to matter, exchange rate flexibility has a marginal positive impact on the likelihood of soft and hard landing credit booms, but no significant differences between them are found.

Additionally, some differences in the credit boom dynamics are found between developed and developing countries. In particular, while economic growth matters for both groups, capital inflows, central bank independence and uncertainty drive the risk of hard landing credit booms in developed countries, central bank interest rate and government stability enhance the risk of hard landing credit booms in developing countries.

From a policy perspective, the findings of this study suggest that measures aimed at stabilising the inflow of capital, promoting sustainable economic growth and financial stability can help to boost the pace of credit booms that end up without collateral damages. Additionally, they also highlight that the monetary authorities should account for the harmful consequences of interest rate rises when credit is growing above its fundamentals. A more vigilant behaviour regarding the build-up of credit bubbles in the economy can help them to smooth the process of increasing the interest rate over time in order to timely adjust the economic agents' expectations.

\section{References}

Agnello, L., Castro, V., Sousa, R., 2012. How does fiscal policy react to wealth composition and asset prices? Journal of Macroeconomics, 34(3), 874-890.

Agnello, L., Castro, V., and Sousa, R., 2015. Booms, busts and normal times in the housing market. Journal of Business and Economic Statistics, 33(1), 25-45.

Agnello, L., Castro, V., and Sousa, R., 2018. The Legacy and the Tyranny of Time: Exit and ReEntry of Sovereigns to International Capital Markets. Journal of Money, Credit and Banking, 50(8), 1969-1994.

Agnello, L., and Sousa, R., 2013. Fiscal policy and asset prices. Bulletin of Economic Research, 65(2), 154-177. 
Akyuz, Y., 2009. The Management of Capital Flows and Financial Vulnerability in Asia. Initiative for Policy Dialogue, Working Paper Series.

Allison, P., 1982. Discrete-time methods for the analysis of event histories. Sociological Methodology, 13, 61-98.

Allison, P., 2014. Event History and Survival Analysis, $2^{\text {nd }}$ Ed. California: Sage Publications.

Arena, M., Bouza, S., Dabla-Norris, M. E., Gerling, M. K., and Njie, L. (2015). Credit Booms and Macroeconomic Dynamics: Stylized Facts and Lessons for Low-Income Countries. International Monetary Fund Working Paper 15/11.

Avdjiev, S., Binder, S., and Sousa, R., 2018. External debt composition and domestic credit cycles. European Stability Mechanism, Working-paper series, 28, 2018.

Barajas, A., Dell'Ariccia, G., and Levchenko, A., 2009. Credit Booms: The Good, the Bad, and the Ugly. Unpublished manuscript, International Monetary Fund (Washington, DC).

Baron, M. and Xiong, W. 2017. Credit Expansion and Neglected Crash Risk. Quarterly Journal of Economics, 132(2), 713-764.

Boissay, F., Collard, F., and Smets, F., 2016. Booms and Banking Crises. Journal of Political Economy, 124(2), 489-538.

Borio, C., 2014. The financial cycle and macroeconomics: what have we learnt? Journal of Banking and Finance, 45(C), 182-198.

Borio, C.,and Disyatat, P., 2011. Global imbalances and the financial crisis: Link or no link? BIS Working Papers No. 346.

Burnside, C., Eichenbaum, M. and Rebelo, S., 2016. Understanding Booms and Busts in Housing Markets. Journal of Political Economy, 124(4), 1088-1147.

Calderón, C. and Kubota, M., 2012.Gross inflows gone wild: gross capital inflows, credit booms and crises. World Bank Policy Research Working Paper No. 6270.

Castro, V., 2010. The duration of economic expansions and recessions: More than duration dependence. Journal of Macroeconomics, 32, 347-365.

Castro, V., 2013. The duration of business cycle expansions and contractions: Are there changepoints in duration dependence? Empirical Economics, 44, 511-544.

Castro, V., and Martins, R., 2013. Is there duration dependence in Portuguese local governments' tenure? European Journal of Political Economy, 31, 26-39. 
Castro, V., and Martins, R., 2019. The political and institutional determinants of credit booms. Oxford Bulletin of Economics and Statistics. DOI: https://doi.org/10.1111/obes.12290

Chappell, H.W., Havrilesky, T.M., and McGregor, R.R., 1993. Partisan monetary policies: presidential influence through the power of appointment. Quarterly Journal of Economics, $108(1), 185-218$.

Dell'Ariccia, G., Igan, D., Laeven, L., and Tong, H., 2016. Credit booms and Macrofinancial Stability. Economic Policy, 31(86), 299-355.

Dell'Ariccia, G., and Marquez R., 2006. Lending Booms and Lending Standards. The Journal of Finance, 51(5), 2511-2546.

Drehmann, M., Borio, C., and Tsatsaronis, K., 2011. Anchoring countercyclical capital buffers: The role of credit aggregates. International Journal of Central Banking, 7(4), 189-240.

Elekdag, S., and Wu, Y., 2013. Rapid Credit Growth in Emerging Markets: Boon or BoomBust? Emerging Markets Finance and Trade, 49(5), 45-62.

Garriga, A., 2016. Central Bank Independence in the World: A New Dataset. International Interactions, 42(5), 849-868.

Gourinchas, P-O, Valdes, R. and Landerretche, O., 2001. Lending Booms: Latin America and the World. Economia Journal, 1(2), 47-99.

Gourinchas, P.-O. and Obstfeld, M., 2012. Stories of the twentieth century for the twenty-first. American Economic Journal: Macroeconomics, 4(1), 226-65.

Havrilesky, T.M.,1988. Monetary policy signalling from the administration to the federal reserve. Journal of Money, Credit and Banking, 20, 82-101.

Havrilesky, T.M., 1991. The frequency of monetary policy signalling from the administration to the federal reserve. Journal of Money, Credit and Banking, 23, 423-428.

Ilzetzky, E., Reinhart, C., Rogoff, K., 2009. Exchange Rate Arrangements Entering the 21st Century: Which Anchor will Hold? Cambridge, MA, Harvard University, manuscript.

Jenkins, S., 2005. Survival analysis. University of Essex. Unpublished manuscript. [https://www.iser.essex.ac.uk/files/teaching/stephenj/ec968/pdfs/ec968lnotesv6.pdf]

Laeven, L., and F. Valencia, 2008. Systemic banking crises: A new database. International Monetary Fund Working Paper 08/224.

Laeven, L., and F. Valencia, 2010. Resolution of banking crises: The good, the bad, and the ugly. International Monetary Fund Working Paper 10/146. 
Laeven, L., and Valencia, F., 2012. Systemic banking crises database: An update. International Monetary Fund Working Paper 12/163.

Lohmann, S., 1998. Federalism and central bank independence: the politics of German monetary policy, 1957-9. World Politics 50, 401-446.

Long, J.S., 1997. Regression Models for Categorical and Limited Dependent Variables. Advanced Qualitative Techniques in the Social Sciences Series, Vol.7. Thousand Oaks, California, CA: Sage Publications.

Long, J.S., Freese, J., 2014. Regression Models for Categorical Dependent Variables Using Stata, 3rd Edition. Texas: Stata Press.

Mendoza, E., and Terrones, M., 2008. An Anatomy of Credit Booms: Evidence from Macro Aggregates and Micro Data. NBER Working Paper No. 14049.

Mendoza, E. and Terrones, M., 2012. An Anatomy of Credit Booms and their Demise. NBER Working Paper No. 18379.

Meng, C. and Gonzalez, R. L., 2017. Credit Booms in Developing Countries: Are They Different from Those in Advanced and Emerging Market Countries? Open Economies Review, 28(3), 547-579.

Prentice, R., and Gloeckler, L., 1978. Regression analysis of grouped survival data with application to the breast cancer data. Biometrics, 34, 57-67.

Reinhart, C., Rogoff, K., 2004. The modern history of exchange rate arrangements: a reinterpretation. Quarterly Journal of Economics, 119(1), 1-48.

Reinhart, C., and Rogoff, K., 2009. The Aftermath of Financial Crises. American Economic Review, 99(2), 466-472.

Sidaoui, J., Ramos-Francia, M., and Cuadra, G., 2011.Global liquidity, capital flows and challenges for policymakers: the Mexican experience. In: Capital flows, commodity price movements and foreign exchange intervention. Bank for International Settlements, BIS Papers No. 57, December.

Stock, J.H. and Yogo, M., 2005. Testing for Weak Instruments in Linear IV Regression. In D.W.K. Andrews \& J.H. Stock (eds.) Identification and Inference for Econometric Models Essays in Honor of Thomas Rothenberg. Cambridge: Cambridge University Press, 80-108. 


\section{List of Tables}

Table 1. The duration of credit booms by kind of landing

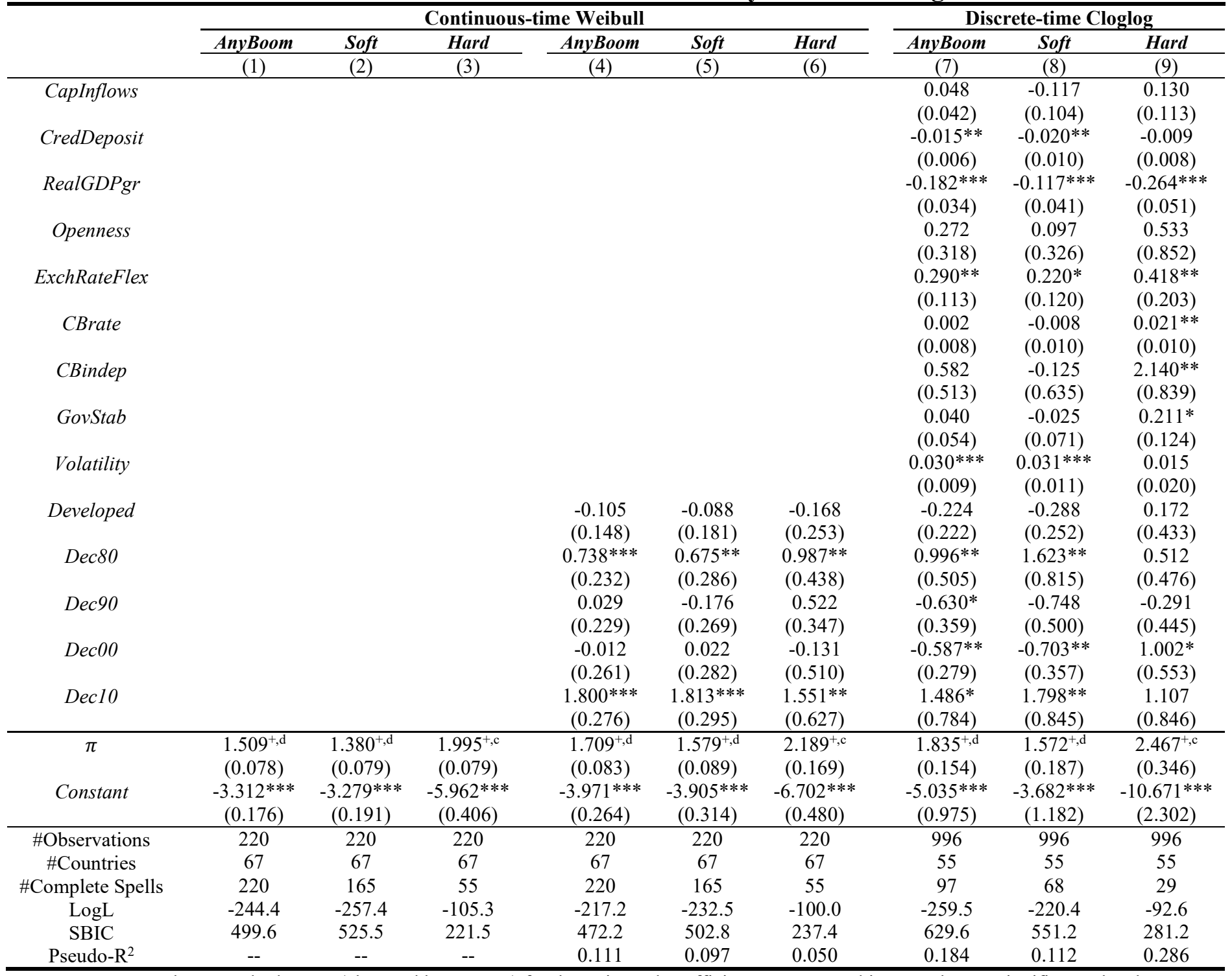

Notes: Robust standard errors (clustered by country) for the estimated coefficients are reported in parentheses. Significance level at which the null is rejected: ***, $1 \% ; * *, 5 \%$; and * $10 \%$. + indicates that $\pi$ is significantly higher than one using a one-sided test with a $5 \%$ significance level; $d, c$, and $i$ indicate decreasing, constant or increasing positive duration dependence, respectively. All regressors are lagged one period to avoid simultaneity problems. The Schwartz Bayesian Information Criterion, $\mathrm{SBIC}=-2 \log \mathrm{L}+\mathrm{k} \log (\mathrm{N})$, where $\mathrm{k}$ is the number of regressors and $\mathrm{N}$ is the number of observations. The McFadden's Pseudo$\mathrm{R}^{2}=1-\log \mathrm{L} / \operatorname{LogL} 0$, where $\operatorname{LogL} 0$ is the $\log$-likelihood of the model with only a constant term. 
Table 2. Determinants of the collapse of credit booms into a soft or hard landing

\begin{tabular}{|c|c|c|c|c|c|c|c|c|c|}
\hline & SL/OCB & HL/OCB & HL/SL & SL/OCB & HL/OCB & HL/SL & SL/OCB & HL/OCB & HL/SL \\
\hline & (1) & (2) & (3) & (4) & (5) & $(6)$ & $(7)$ & (8) & $(9)$ \\
\hline \multirow[t]{2}{*}{ CapInflows } & -0.143 & 0.128 & $0.272 * *$ & -0.152 & 0.103 & $0.255^{* *}$ & -0.161 & 0.144 & $0.305^{* *}$ \\
\hline & $(0.128)$ & $(0.098)$ & $(0.119)$ & $(0.127)$ & $(0.093)$ & $(0.117)$ & $(0.135)$ & $(0.104)$ & $(0.133)$ \\
\hline \multirow[t]{2}{*}{ CredDeposit } & $-0.023 * *$ & -0.014 & 0.008 & $-0.021^{*}$ & -0.012 & 0.009 & $-0.023 * *$ & -0.006 & 0.017 \\
\hline & $(0.011)$ & $(0.010)$ & $(0.012)$ & $(0.011)$ & $(0.010)$ & $(0.012)$ & $(0.011)$ & $(0.010)$ & $(0.015)$ \\
\hline \multirow[t]{2}{*}{ RealGDPgr } & $-0.174 * * *$ & $-0.342 * * *$ & $-0.168 * * *$ & $-0.160 * * *$ & $-0.319 * * *$ & $-0.159 * * *$ & $-0.156^{* * *}$ & $-0.391 * * *$ & $-0.234 * * *$ \\
\hline & $(0.055)$ & $(0.066)$ & $(0.064)$ & $(0.051)$ & $(0.055)$ & $(0.060)$ & $(0.054)$ & $(0.075)$ & $(0.072)$ \\
\hline \multirow[t]{2}{*}{ Openness } & 0.272 & 0.713 & 0.441 & 0.233 & 0.678 & 0.446 & 0.311 & 0.487 & 0.177 \\
\hline & $(0.293)$ & $(0.708)$ & $(0.738)$ & $(0.264)$ & $(0.639)$ & $(0.680)$ & (0.309) & $(0.662)$ & $(0.689)$ \\
\hline \multirow[t]{2}{*}{ ExchRateFlex } & $0.237 *$ & $0.417 *$ & 0.180 & 0.216 & 0.313 & 0.097 & $0.242 *$ & 0.370 & 0.129 \\
\hline & $(0.134)$ & $(0.251)$ & $(0.276)$ & $(0.133)$ & $(0.258)$ & $(0.271)$ & $(0.130)$ & $(0.244)$ & $(0.276)$ \\
\hline \multirow[t]{2}{*}{ CBrate } & -0.005 & $0.026^{* *}$ & $0.031 * *$ & -0.008 & 0.022 & $0.030^{*}$ & -0.003 & $0.032 * *$ & $0.035^{*}$ \\
\hline & $(0.010)$ & $(0.012)$ & $(0.014)$ & $(0.010)$ & $(0.016)$ & $(0.016)$ & (0.009) & $(0.016)$ & $(0.018)$ \\
\hline \multirow[t]{2}{*}{ CBindep } & 0.122 & $2.483 * * *$ & $2.361 * *$ & 0.021 & $1.941 * *$ & $1.920^{*}$ & 0.185 & $2.967 * * *$ & $2.783^{* *}$ \\
\hline & $(0.682)$ & $(0.914)$ & (1.169) & $(0.654)$ & $(0.873)$ & (1.135) & $(0.672)$ & $(0.976)$ & $(1.261)$ \\
\hline \multirow[t]{2}{*}{ GovStab } & -0.013 & $0.223^{*}$ & 0.235 & -0.012 & $0.240^{*}$ & 0.252 & -0.053 & $0.245^{*}$ & $0.298^{*}$ \\
\hline & $(0.072)$ & $(0.125)$ & $(0.151)$ & $(0.071)$ & $(0.140)$ & (0.169) & $(0.073)$ & $(0.126)$ & $(0.157)$ \\
\hline \multirow[t]{2}{*}{ Volatility } & $0.036 * * *$ & 0.031 & -0.005 & $0.037 * * *$ & 0.032 & -0.005 & $0.036 * * *$ & 0.028 & -0.008 \\
\hline & $(0.012)$ & $(0.022)$ & $(0.024)$ & $(0.012)$ & $(0.022)$ & $(0.025)$ & $(0.013)$ & $(0.020)$ & $(0.023)$ \\
\hline \multirow[t]{2}{*}{ Developed } & -0.372 & 0.164 & 0.536 & -0.384 & -0.008 & 0.376 & -0.251 & 0.336 & 0.588 \\
\hline & $(0.278)$ & $(0.510)$ & $(0.519)$ & $(0.268)$ & $(0.540)$ & $(0.543)$ & $(0.271)$ & $(0.565)$ & $(0.642)$ \\
\hline \multirow[t]{2}{*}{ LnDurCBoom } & $0.719 * * *$ & $1.699 * * *$ & $0.981 * *$ & & & & & & \\
\hline & $(0.212)$ & $(0.365)$ & $(0.435)$ & & & & & & \\
\hline DurCBoom & & & & $\begin{array}{c}0.061 * * * \\
(0.020)\end{array}$ & $\begin{array}{c}0.138 * * * \\
(0.035)\end{array}$ & $\begin{array}{l}0.078 * \\
(0.041)\end{array}$ & & & \\
\hline D_Dur_yrl & & & & & & & $-1.083^{*}$ & $-18.117 * * *$ & $-17.034 * * *$ \\
\hline \multirow[t]{2}{*}{ D_Dur_yr2 } & & & & & & & $\begin{array}{l}(0.603) \\
-0.119\end{array}$ & $\begin{array}{c}(0.86 /) \\
-1.458 * *\end{array}$ & $\begin{array}{l}(1.139) \\
-1.339\end{array}$ \\
\hline & & & & & & & $(0.445)$ & $(0.640)$ & $(0.916)$ \\
\hline \multirow[t]{2}{*}{ D_Dur_yr3 } & & & & & & & 0.417 & $-1.785^{* *}$ & $-2.202 * *$ \\
\hline & & & & & & & $(0.465)$ & $(0.758)$ & $(0.952)$ \\
\hline \multirow[t]{2}{*}{ D_Dur_yr4 } & & & & & & & 0.415 & $-1.935 * *$ & $-2.350 * *$ \\
\hline & & & & & & & $(0.544)$ & $(0.961)$ & $(1.066)$ \\
\hline \multirow[t]{2}{*}{ D_Dur_yr 5} & & & & & & & 0.070 & 0.016 & -0.054 \\
\hline & & & & & & & $(0.654)$ & $(0.853)$ & $(1.051)$ \\
\hline \#Observations & & 996 & & & 996 & & & 996 & \\
\hline \#Countries & & 55 & & & 55 & & & 55 & \\
\hline \#Spells & 68 & 29 & & 68 & 29 & & 68 & 29 & \\
\hline $\log L$ & & -304.1 & & & -311.0 & & & -296.8 & \\
\hline SBIC & & 829.2 & & & 842.8 & & & 869.8 & \\
\hline Pseudo-R ${ }^{2}$ & & 0.194 & & & 0.176 & & & 0.213 & \\
\hline IIA tests & & & & & & & & & \\
\hline Suest-Hausman & nitted catego & & & & & & & & \\
\hline OCB & & 19.489 & & & 10.119 & & & 22.451 & \\
\hline & & {$[0.244]$} & & & {$[0.860]$} & & & {$[0.317]$} & \\
\hline SL & & 16.789 & & & 16.281 & & & 18.810 & \\
\hline & & [0.399] & & & {$[0.434]$} & & & {$[0.534]$} & \\
\hline HL & & 8.676 & & & 8.160 & & & 9.883 & \\
\hline & & {$[0.926]$} & & & {$[0.944]$} & & & {$[0.970]$} & \\
\hline Small-Hsiao: o & ed category & & & & & & & & \\
\hline $\mathrm{OCB}$ & & 24.582 & & & 23.483 & & & 26.201 & \\
\hline & & {$[0.078]$} & & & [0.101] & & & [0.159] & \\
\hline SL & & 20.725 & & & 22.943 & & & 30.263 & \\
\hline & & {$[0.189]$} & & & {$[0.115]$} & & & {$[0.066]$} & \\
\hline HL & & 12.085 & & & 14.499 & & & 21.621 & \\
\hline & & {$[0.738]$} & & & {$[0.562]$} & & & {$[0.361]$} & \\
\hline
\end{tabular}

Notes: See Table 1. Robust standard errors (clustered by country) for the estimated coefficients are reported in parentheses. Significance level at which the null is rejected: ***, 1\%; **, 5\%; and *, 10\%. Time-effects are accounted for with decade dummies. OCB $=$ Ongoing Credit Boom; $\mathrm{SL}=$ Soft Landing; $\mathrm{HL}=$ Hard Landing. \#Spells indicates the number of episodes of soft and hard landings, respectively. The variables are lagged one period to avoid simultaneity problems. The suest-based Hausman and Small-Hsiao tests for the independence of irrelevant alternatives (IIA) are reported here to assess whether the risks are independent or not; for each statistic of the test is also reported the respective p-value in square brackets; 16 degrees of freedom are considered in the first two estimations and 20 when the dummies for duration are used instead. 
Table 3. Endogeneity and alternative definitions of credit booms

\begin{tabular}{|c|c|c|c|c|c|c|c|c|c|}
\hline & \multicolumn{3}{|c|}{ Endogeneity } & \multicolumn{3}{|c|}{ Threshold: 1.75} & \multicolumn{3}{|c|}{ Threshold: 2.0} \\
\hline & SL/OCB & HL/OCB & HL/SL & SL/OCB & HL/OCB & HL/SL & SL/OCB & HL/OCB & HL/SL \\
\hline & (1) & (2) & (3) & (4) & (5) & $(6)$ & $(7)$ & (8) & $(9)$ \\
\hline \multirow[t]{2}{*}{ CapInflows } & -0.730 & 0.173 & 0.903 & -0.069 & 0.098 & 0.167 & -0.054 & 0.103 & 0.156 \\
\hline & $(0.827)$ & $(0.138)$ & $(0.842)$ & $(0.134)$ & $(0.127)$ & $(0.145)$ & $(0.132)$ & $(0.132)$ & $(0.148)$ \\
\hline \multirow[t]{2}{*}{ CredDeposit } & $-0.023 *$ & -0.016 & 0.008 & $-0.019 *$ & $-0.020 * *$ & -0.001 & $-0.022 *$ & $-0.019 * *$ & 0.002 \\
\hline & $(0.012)$ & $(0.011)$ & $(0.011)$ & $(0.011)$ & $(0.009)$ & $(0.013)$ & $(0.013)$ & $(0.009)$ & $(0.015)$ \\
\hline \multirow[t]{2}{*}{ RealGDPgr } & $-0.159 * * *$ & $-0.355^{* * *}$ & $-0.196 * * *$ & $-0.159 * * *$ & $-0.334 * * *$ & $-0.176 * *$ & $-0.143 * * *$ & $-0.328 * * *$ & $-0.185^{* *}$ \\
\hline & $(0.054)$ & $(0.072)$ & $(0.073)$ & $(0.055)$ & $(0.070)$ & $(0.072)$ & $(0.050)$ & $(0.069)$ & $(0.074)$ \\
\hline \multirow[t]{2}{*}{ Openness } & 0.518 & 0.572 & 0.054 & 0.111 & 1.191 & 1.080 & -0.036 & 1.128 & 1.164 \\
\hline & $(0.408)$ & $(0.786)$ & $(0.816)$ & $(0.463)$ & $(0.888)$ & $(0.920)$ & $(0.499)$ & $(0.934)$ & $(0.984)$ \\
\hline \multirow[t]{2}{*}{ ExchRateFlex } & $0.228 *$ & 0.386 & 0.158 & $0.229 *$ & $0.572 * *$ & 0.343 & 0.212 & $0.571^{* *}$ & 0.359 \\
\hline & $(0.134)$ & $(0.247)$ & $(0.260)$ & $(0.133)$ & $(0.275)$ & $(0.282)$ & $(0.147)$ & $(0.274)$ & $(0.296)$ \\
\hline \multirow[t]{2}{*}{ CBrate } & -0.004 & $0.028 * *$ & $0.031 * *$ & -0.003 & $0.023^{*}$ & $0.026 * *$ & -0.003 & $0.022^{*}$ & $0.025^{*}$ \\
\hline & $(0.009)$ & $(0.011)$ & $(0.013)$ & $(0.009)$ & $(0.013)$ & $(0.012)$ & $(0.010)$ & $(0.013)$ & $(0.013)$ \\
\hline \multirow[t]{2}{*}{ CBindep } & 0.180 & $2.598 * * *$ & $2.419 * *$ & 0.284 & $2.565 * *$ & $2.281^{*}$ & 0.426 & $2.591 * * *$ & $2.166^{*}$ \\
\hline & $(0.680)$ & $(0.901)$ & $(1.130)$ & $(0.754)$ & $(1.013)$ & $(1.204)$ & $(0.763)$ & $(1.002)$ & $(1.237)$ \\
\hline \multirow[t]{2}{*}{ GovStab } & 0.006 & $0.210^{*}$ & 0.204 & -0.064 & $0.342 * *$ & $0.406 * * *$ & -0.077 & $0.342 * *$ & $0.419 * * *$ \\
\hline & $(0.076)$ & $(0.122)$ & $(0.149)$ & $(0.076)$ & $(0.134)$ & $(0.151)$ & $(0.081)$ & $(0.134)$ & $(0.152)$ \\
\hline \multirow[t]{2}{*}{ Volatility } & $0.033 * * *$ & 0.032 & -0.000 & $0.039 * * *$ & 0.015 & -0.024 & $0.036 * * *$ & 0.015 & -0.021 \\
\hline & $(0.012)$ & $(0.021)$ & $(0.024)$ & $(0.012)$ & $(0.025)$ & $(0.027)$ & $(0.012)$ & $(0.025)$ & $(0.028)$ \\
\hline \multirow[t]{2}{*}{ Developed } & -0.324 & 0.085 & 0.408 & -0.342 & 0.132 & 0.474 & -0.348 & 0.163 & 0.510 \\
\hline & $(0.310)$ & $(0.508)$ & $(0.508)$ & -0.069 & 0.098 & 0.167 & -0.054 & 0.103 & 0.156 \\
\hline \multirow[t]{2}{*}{ LnDurCBoom } & $0.681^{* * *}$ & $1.756^{* * *}$ & $1.075^{* *}$ & $0.669 * * *$ & $2.194 * * *$ & $1.525 * * *$ & $0.607 * * *$ & $2.157 * * *$ & $1.550 * * *$ \\
\hline & $(0.210)$ & $(0.375)$ & $(0.444)$ & $(0.216)$ & $(0.421)$ & $(0.503)$ & $(0.213)$ & $(0.422)$ & $(0.504)$ \\
\hline \#Observations & \multicolumn{3}{|l|}{982} & \multicolumn{3}{|l|}{939} & \multicolumn{3}{|l|}{905} \\
\hline \#Countries & \multicolumn{3}{|l|}{55} & \multicolumn{3}{|l|}{54} & \multicolumn{3}{|l|}{54} \\
\hline \#Spells & \multirow[t]{8}{*}{68} & 29 & & 64 & 25 & & 62 & 25 & \\
\hline $\log L$ & & -303.6 & & & -275.1 & & & -267.7 & \\
\hline SBIC & & 827.6 & & & 769.2 & & & 753.3 & \\
\hline Pseudo-R ${ }^{2}$ & & 0.192 & & & 0.208 & & & 0.209 & \\
\hline Cragg-Donald & & 257.6 & & & & & & & \\
\hline Kleibergen-Paap & & 22.7 & & & & & & & \\
\hline Stock-Yogo $(5 \%)$ & & 17.80 & & & & & & & \\
\hline Durbin-Wu-Hausman & & $\begin{array}{c}7.73 \\
0.259]\end{array}$ & & & & & & & \\
\hline
\end{tabular}

Notes: See Tables 1 and 2. Results from instrumental variable (IV) estimations where CapInflows, CredDeposit and RealGDPgr are instrumented with their lags one to four. The predicted values from the first-stage estimation for those variables are then used in the second-stage multinomial logit estimations. The F-statistics for the Cragg-Donald and Kleibergen-Paap weak identification tests are reported at the bottom of the table, with the respective Stock-Yogo weak identification critical values for a 5\% maximal IV relative bias. The values for the Durbin-Wu-Hausman endogeneity test statistic are reported in the last row with the respective $p$-values in square-brackets. 
Table 4. Developed versus Developing/Emerging countries

\begin{tabular}{|c|c|c|c|c|c|c|}
\hline & \multicolumn{3}{|c|}{ Developed countries } & \multicolumn{3}{|c|}{ Developing/Emerging countries } \\
\hline & SL/OCB & HL/OCB & HL/SL & SL/OCB & HL/OCB & HL/SL \\
\hline & $(1)$ & $(2)$ & $(3)$ & $(4)$ & $(5)$ & $(6)$ \\
\hline \multirow[t]{2}{*}{ CapInflows } & -0.158 & 0.100 & $0.258 * *$ & 0.144 & 4.888 & 4.744 \\
\hline & $(0.125)$ & $(0.079)$ & $(0.111)$ & $(2.278)$ & $(7.332)$ & $(8.129)$ \\
\hline \multirow[t]{2}{*}{ CredDeposit } & -0.003 & 0.039 & 0.042 & -0.001 & -0.034 & -0.033 \\
\hline & $(0.046)$ & $(0.062)$ & $(0.088)$ & $(0.018)$ & $(0.026)$ & $(0.034)$ \\
\hline \multirow[t]{2}{*}{ RealGDPgr } & $-0.233 * * *$ & $-0.341 * * *$ & -0.108 & -0.109 & $-0.499 * * *$ & $-0.390 * *$ \\
\hline & $(0.074)$ & $(0.098)$ & $(0.089)$ & $(0.089)$ & $(0.190)$ & $(0.199)$ \\
\hline \multirow[t]{2}{*}{ Openness } & 0.455 & 1.020 & 0.565 & -1.055 & -0.877 & 0.178 \\
\hline & $(0.322)$ & $(0.632)$ & $(0.723)$ & $(0.832)$ & $(1.047)$ & $(1.291)$ \\
\hline \multirow[t]{2}{*}{ ExchRateFlex } & 0.287 & $0.627 *$ & 0.339 & 0.248 & 0.300 & 0.052 \\
\hline & $(0.188)$ & $(0.342)$ & $(0.374)$ & $(0.213)$ & $(0.370)$ & $(0.356)$ \\
\hline \multirow[t]{2}{*}{ CBrate } & -0.010 & -0.043 & -0.033 & 0.003 & $0.043 * * *$ & 0.039 \\
\hline & $(0.025)$ & $(0.064)$ & $(0.066)$ & $(0.028)$ & $(0.013)$ & $(0.028)$ \\
\hline \multirow[t]{2}{*}{ CBindep } & 0.737 & $2.663 * *$ & 1.926 & 0.366 & 1.233 & 0.867 \\
\hline & $(0.862)$ & $(1.224)$ & $(1.505)$ & $(1.554)$ & (3.929) & $(4.177)$ \\
\hline \multirow[t]{2}{*}{ GovStab } & 0.081 & 0.009 & -0.072 & -0.209 & $0.519 * *$ & $0.727 * * *$ \\
\hline & $(0.110)$ & $(0.165)$ & $(0.190)$ & $(0.137)$ & $(0.244)$ & $(0.282)$ \\
\hline \multirow[t]{2}{*}{ Volatility } & $0.028 *$ & $0.052 * *$ & 0.025 & 0.030 & 0.001 & -0.029 \\
\hline & $(0.014)$ & $(0.023)$ & $(0.027)$ & $(0.025)$ & $(0.031)$ & $(0.037)$ \\
\hline \multirow[t]{2}{*}{ LnDurCBoom } & $0.595 * *$ & $1.225 * * *$ & 0.630 & $1.586 * * *$ & $3.304^{* * *}$ & 1.718 \\
\hline & $(0.292)$ & $(0.459)$ & $(0.575)$ & $(0.446)$ & $(1.059)$ & $(1.125)$ \\
\hline \#Observations & & 602 & & & 394 & \\
\hline \#Countries & & 35 & & & 20 & \\
\hline \#Spells & 41 & 18 & & 27 & 11 & \\
\hline $\log L$ & & -188.5 & & & -98.5 & \\
\hline SBIC & & 569.0 & & & 316.5 & \\
\hline Pseudo-R ${ }^{2}$ & & 0.178 & & & 0.334 & \\
\hline
\end{tabular}

Notes: See Tables 1 and 2. 


\section{List of Figures}

Figure 1. Credit booms, soft and hard landings: frequency and survival

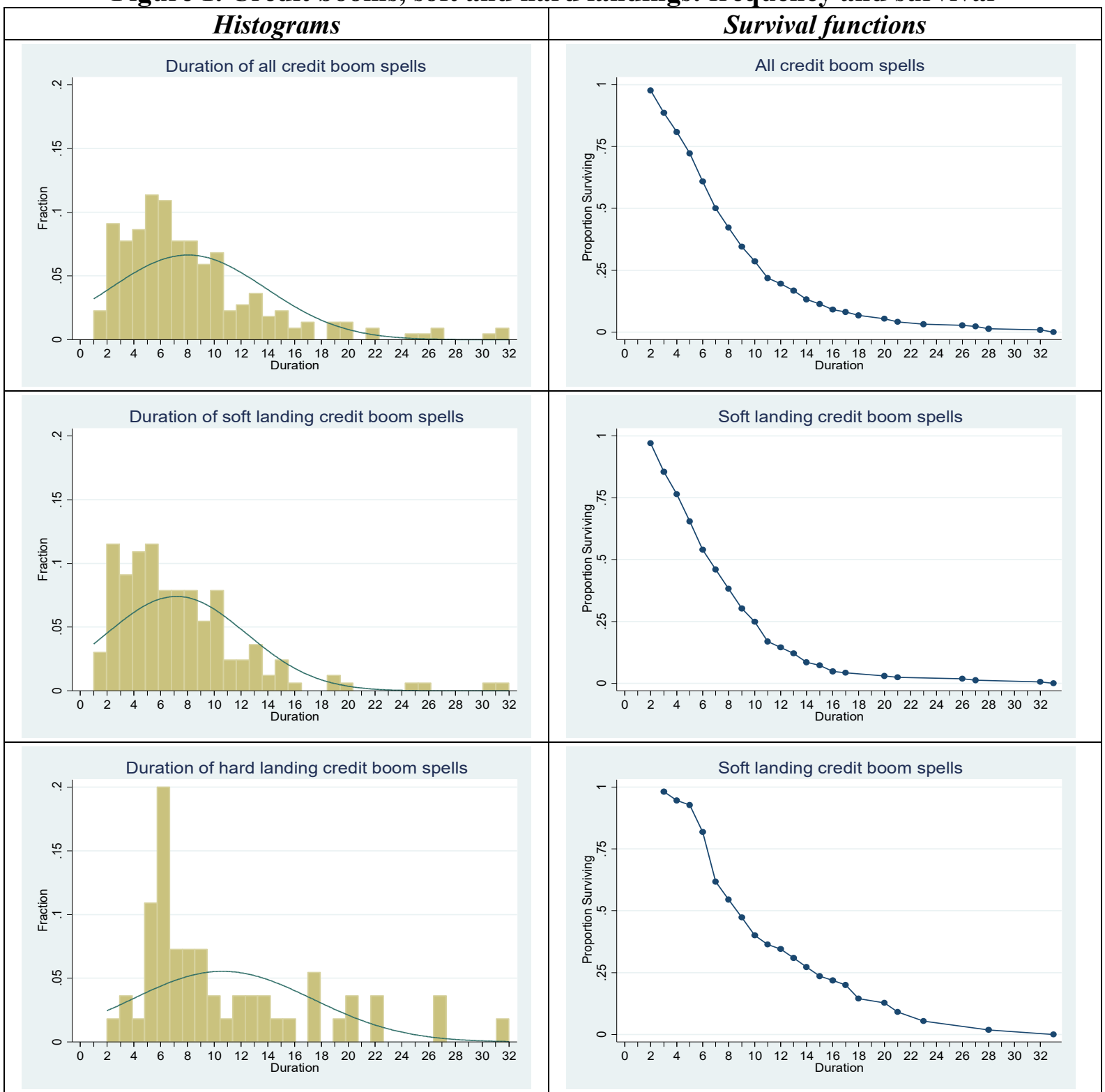

Figure 2. Estimated Hazard functions by kind of event

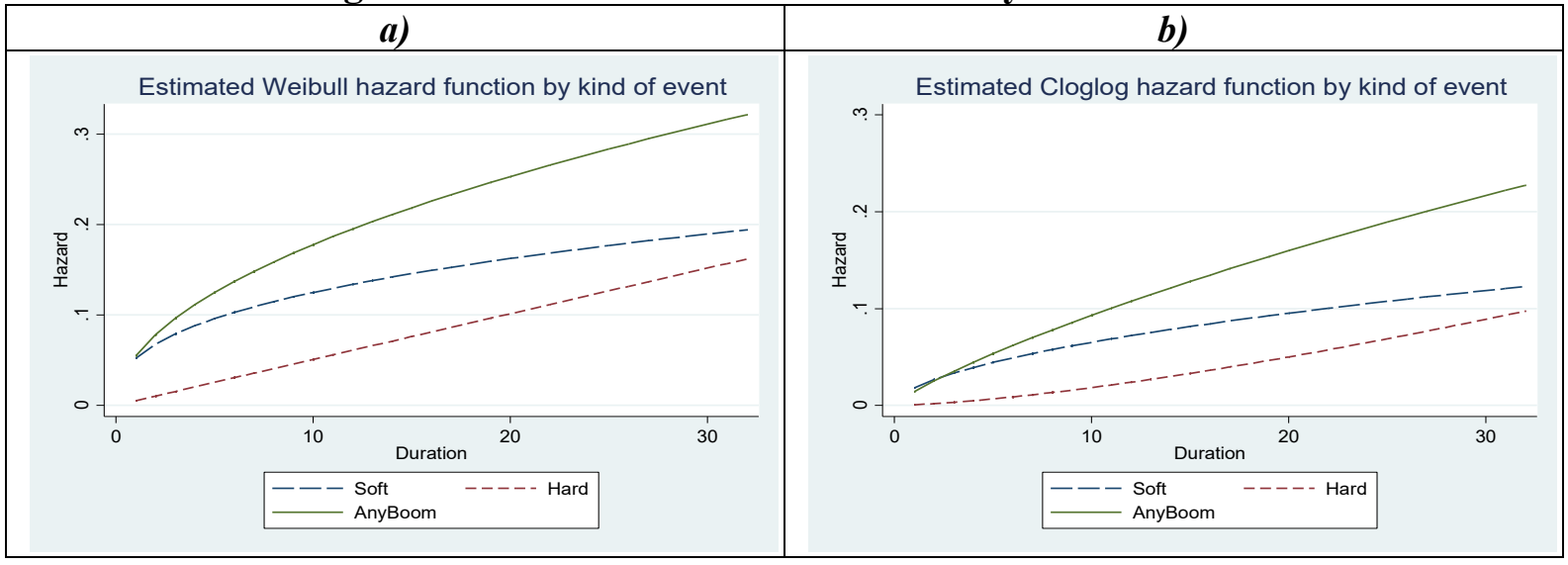




\section{APPENDIX}

Table A1. Credit booms dates, duration and kind

\begin{tabular}{|c|c|c|c|c|c|c|c|c|c|}
\hline Country & Begin & End & Duration & Outcome & Country & Begin & End & Duration & Outcome \\
\hline Argentina & $1984 q 1$ & $1985 q 4$ & 8 & Soft & Ecuador & $1981 \mathrm{q} 3$ & $1982 q 1$ & 3 & Hard \\
\hline Argentina & $1989 q 2$ & 1991q2 & 9 & Hard & Ecuador & $1984 q 1$ & $1985 q 4$ & 8 & Soft \\
\hline Argentina & $1997 q 1$ & $1999 q 1$ & 9 & Hard & Ecuador & $1993 q 3$ & $1995 q 4$ & 10 & Soft \\
\hline Armenia & $1994 q 3$ & $1995 \mathrm{q} 3$ & 5 & Soft & Ecuador & $1997 \mathrm{q} 3$ & $1998 \mathrm{q} 4$ & 6 & Hard \\
\hline Armenia & $1999 q 2$ & $2000 q 4$ & 7 & Soft & Ecuador & $2001 \mathrm{q} 1$ & $2002 q 2$ & 6 & Soft \\
\hline Armenia & $2004 q 3$ & $2009 q 1$ & 19 & Soft & El Salvador & $1984 q 4$ & $1985 q 4$ & 5 & Soft \\
\hline Armenia & $2012 q 1$ & $2013 q 1$ & 5 & Soft & El Salvador & $1988 \mathrm{q} 4$ & $1990 q 1$ & 6 & Hard \\
\hline Armenia & $2014 q 4$ & $2015 q 1$ & 2 & Soft & El Salvador & $1993 q 4$ & $1996 q 1$ & 10 & Soft \\
\hline Australia & $1985 \mathrm{q} 1$ & $1986 \mathrm{q} 3$ & 7 & Soft & Estonia & $1992 \mathrm{q} 2$ & $1992 q 4$ & 3 & Hard \\
\hline Australia & $1989 q 1$ & $1991 \mathrm{q} 2$ & 10 & Soft & Estonia & $1996 \mathrm{q} 2$ & $1998 \mathrm{q} 2$ & 9 & Soft \\
\hline Australia & $2007 q 4$ & $2009 q 2$ & 7 & Soft & Estonia & $2005 q 3$ & $2009 q 1$ & 15 & Soft \\
\hline Austria & $1997 \mathrm{q} 1$ & $1998 \mathrm{q} 3$ & 7 & Soft & Finland & $1989 q 1$ & $1993 q 1$ & 17 & Hard \\
\hline Austria & $2005 q 2$ & $2006 \mathrm{q} 3$ & 6 & Hard & Finland & $2007 q 4$ & $2008 \mathrm{q} 4$ & 5 & Soft \\
\hline Belgium & $1992 q 4$ & $1994 q 3$ & 8 & Soft & Finland & $2012 q 4$ & $2013 q 4$ & 5 & Soft \\
\hline Bolivia & $1977 q 1$ & $1977 q 4$ & 4 & Soft & France & $1978 \mathrm{q} 1$ & $1979 q 4$ & 8 & Soft \\
\hline Bolivia & $1982 \mathrm{q} 1$ & $1982 q 3$ & 3 & Soft & France & $2007 q 3$ & $2008 q 4$ & 6 & Hard \\
\hline Bolivia & $1984 q 4$ & $1987 q 1$ & 10 & Hard & Germany & $1975 q 1$ & $1975 q 2$ & 2 & Soft \\
\hline Bolivia & $1990 \mathrm{q} 2$ & $1995 q 1$ & 20 & Hard & Germany & $2000 \mathrm{q} 1$ & $2001 \mathrm{q} 4$ & 8 & Soft \\
\hline Bolivia & $1996 \mathrm{q} 4$ & $1998 \mathrm{q} 4$ & 9 & Soft & Germany & $2008 \mathrm{q} 4$ & $2009 q 3$ & 4 & Soft \\
\hline Bolivia & $2012 q 1$ & $2012 q 1$ & 1 & Soft & Greece & $1978 \mathrm{q} 4$ & $1979 q 4$ & 5 & Soft \\
\hline Bolivia & $2013 q 1$ & $2013 q 2$ & 2 & Soft & Greece & $2007 \mathrm{q} 3$ & $2008 \mathrm{q} 4$ & 7 & Hard \\
\hline Brazil & $1989 q 3$ & $1990 \mathrm{q} 3$ & 5 & Hard & Greece & $2010 q 2$ & $2011 q 1$ & 4 & Soft \\
\hline Brazil & $1992 q 2$ & $1995 q 1$ & 12 & Hard & Greece & $2012 q 1$ & $2013 q 1$ & 5 & Hard \\
\hline Brazil & $2006 \mathrm{q} 3$ & $2008 \mathrm{q} 4$ & 10 & Soft & Hungary & $1987 \mathrm{q} 1$ & $1991 \mathrm{q} 1$ & 17 & Hard \\
\hline Brazil & $2012 q 1$ & $2013 q 1$ & 5 & Soft & Hungary & $2000 q 1$ & 2001q1 & 5 & Soft \\
\hline Bulgaria & $1996 \mathrm{q} 4$ & $1997 \mathrm{q} 3$ & 4 & Soft & Hungary & $2003 q 2$ & $2004 q 3$ & 6 & Soft \\
\hline Bulgaria & $2001 \mathrm{q} 4$ & $2009 q 3$ & 32 & Soft & Hungary & $2007 q 4$ & $2009 q 1$ & 6 & Hard \\
\hline Bulgaria & $2012 q 2$ & $2012 q 3$ & 2 & Soft & Iceland & $1982 \mathrm{q} 1$ & $1983 q 4$ & 8 & Soft \\
\hline Canada & $1981 \mathrm{q} 2$ & $1982 q 3$ & 6 & Soft & Iceland & $1989 q 4$ & $1990 q 1$ & 2 & Soft \\
\hline Canada & $2001 \mathrm{q} 4$ & $2003 q 2$ & 7 & Soft & Iceland & $1997 q 4$ & $2001 \mathrm{q} 2$ & 15 & Soft \\
\hline Canada & $2006 \mathrm{q} 3$ & $2006 q 4$ & 2 & Soft & Iceland & $2004 q 1$ & $2008 \mathrm{q} 3$ & 19 & Hard \\
\hline Chile & $1976 \mathrm{q} 3$ & $1978 \mathrm{q} 3$ & 9 & Soft & India & $2000 \mathrm{q} 2$ & $2001 \mathrm{q} 1$ & 4 & Soft \\
\hline Chile & $1979 q 3$ & $1983 q 2$ & 16 & Hard & India & $2002 q 2$ & $2002 q 3$ & 2 & Soft \\
\hline Chile & $1984 \mathrm{q} 3$ & $1985 \mathrm{q} 1$ & 3 & Soft & India & $2006 \mathrm{q} 3$ & $2008 \mathrm{q} 4$ & 10 & Soft \\
\hline Chile & $2007 q 3$ & $2009 q 1$ & 7 & Soft & Indonesia & $1986 q 4$ & $1991 q 2$ & 19 & Soft \\
\hline Colombia & $1984 \mathrm{q} 3$ & $1985 q 4$ & 6 & Soft & Indonesia & $1997 \mathrm{q} 3$ & $1998 \mathrm{q} 4$ & 6 & Hard \\
\hline Colombia & $1997 \mathrm{q} 3$ & $1999 q 2$ & 8 & Hard & Indonesia & $2012 q 4$ & $2013 q 4$ & 5 & Soft \\
\hline Colombia & $2006 \mathrm{q} 3$ & $2009 q 1$ & 11 & Soft & Ireland & $2006 \mathrm{q} 4$ & $2009 q 3$ & 12 & Hard \\
\hline Costa Rica & $1992 q 4$ & $1994 q 3$ & 8 & Hard & Israel & $1977 q 4$ & $1978 \mathrm{q} 4$ & 5 & Soft \\
\hline Costa Rica & $1996 \mathrm{q} 2$ & $1994 q 4$ & 3 & Soft & Israel & 1984q1 & $1986 q 2$ & 10 & Soft \\
\hline Costa Rica & $1998 \mathrm{q} 1$ & $2001 \mathrm{q} 1$ & 13 & Soft & Italy & $1991 q 4$ & $1993 q 4$ & 9 & Soft \\
\hline Costa Rica & $2007 q 1$ & $2009 \mathrm{q} 3$ & 8 & Soft & Italy & $1999 q 1$ & $2001 \mathrm{q} 4$ & 12 & Soft \\
\hline Croatia & $1993 q 4$ & $1994 q 2$ & 3 & Soft & Italy & $2010 \mathrm{q} 2$ & $2011 \mathrm{q} 3$ & 4 & Soft \\
\hline Croatia & $1997 q 4$ & $1998 \mathrm{q} 4$ & 5 & Hard & Japan & $1998 \mathrm{q} 2$ & $2001 \mathrm{q} 3$ & 14 & Soft \\
\hline Croatia & $2001 \mathrm{q} 1$ & $2003 q 3$ & 11 & Soft & Kenya & $1977 \mathrm{q} 3$ & $1979 q 1$ & 7 & Soft \\
\hline Croatia & $2012 q 1$ & $2012 q 2$ & 2 & Soft & Kenya & $1992 q 2$ & $1993 q 1$ & 4 & Soft \\
\hline Croatia & $2014 q 4$ & $2015 q 1$ & 2 & Soft & Kenya & $1995 \mathrm{q} 2$ & $1996 \mathrm{q} 2$ & 5 & Soft \\
\hline Cyprus & $1988 \mathrm{q} 4$ & $1989 \mathrm{q} 3$ & 4 & Soft & Kenya & $1997 \mathrm{q} 3$ & $1997 q 4$ & 2 & Soft \\
\hline Cyprus & $2000 \mathrm{q} 1$ & $2001 \mathrm{q} 4$ & 8 & Soft & Kenya & $1999 q 2$ & $2000 \mathrm{q} 1$ & 4 & Soft \\
\hline Cyprus & $2007 q 1$ & $2009 q 3$ & 11 & Soft & Kenya & $2008 \mathrm{q} 2$ & $2009 q 1$ & 4 & Soft \\
\hline Czech Rep. & $1996 q 2$ & $1998 \mathrm{q} 3$ & 10 & Soft & Kenya & $2011 q 2$ & 201141 & 3 & Soft \\
\hline Czech Rep. & $2005 \mathrm{q} 2$ & $2008 \mathrm{q} 3$ & 14 & Soft & Korea Rep. & $2002 q 2$ & $2004 q 1$ & 9 & Soft \\
\hline Denmark & $1986 \mathrm{q} 3$ & $1986 q 4$ & 2 & Soft & Korea Rep. & $2008 \mathrm{q} 1$ & $2009 q 2$ & 6 & Soft \\
\hline Denmark & $1987 q 4$ & $1990 \mathrm{q} 4$ & 13 & Soft & Latvia & $1997 \mathrm{q} 2$ & $1999 q 1$ & 8 & Soft \\
\hline Denmark & $2000 \mathrm{q} 3$ & $2000 q 4$ & 2 & Soft & Latvia & $2000 q 3$ & $2008 \mathrm{q} 2$ & 32 & Hard \\
\hline Dominican Rep. & $1989 q 1$ & $1989 q 4$ & 4 & Soft & Latvia & $2009 q 3$ & $2008 \mathrm{q} 3$ & 1 & Soft \\
\hline Dominican Rep. & $2003 \mathrm{q} 1$ & $2004 q 2$ & 6 & Hard & & & & & (Cont.) \\
\hline
\end{tabular}


Table A1. Credit booms dates, duration and kind (Cont.)

\begin{tabular}{|c|c|c|c|c|c|c|c|c|c|}
\hline Country & Begin & End & Duration & Outcome & Country & Begin & End & Duration & Outcome \\
\hline Lithuania & $1993 q 3$ & $1993 q 4$ & 2 & Hard & Romania & $1998 \mathrm{q} 3$ & $1999 q 1$ & 3 & Soft \\
\hline Lithuania & $1998 \mathrm{q} 2$ & $1999 \mathrm{q} 3$ & 6 & Soft & Romania & $2001 \mathrm{q} 4$ & $2009 q 2$ & 31 & Soft \\
\hline Lithuania & $2002 q 3$ & $2008 \mathrm{q} 4$ & 26 & Soft & Russian Fed. & $1994 q 3$ & $1995 \mathrm{q} 3$ & 5 & Soft \\
\hline Luxembourg & $1982 \mathrm{q} 1$ & $1982 \mathrm{q} 3$ & 3 & Soft & Russian Fed. & $1998 \mathrm{q} 3$ & $2002 q 2$ & 16 & Soft \\
\hline Luxembourg & $1988 \mathrm{q} 1$ & $1988 \mathrm{q} 3$ & 3 & Soft & Russian Fed. & $2006 q 1$ & $2009 q 2$ & 14 & Hard \\
\hline Luxembourg & $2005 q 2$ & $2006 q 4$ & 7 & Hard & Russian Fed. & $2013 q 1$ & $2014 q 1$ & 5 & Hard \\
\hline Luxembourg & $2007 q 4$ & $2008 \mathrm{q} 4$ & 5 & Hard & Slovak Republic & $1993 q 1$ & $1993 q 4$ & 4 & Soft \\
\hline Malaysia & $1979 q 4$ & $1982 \mathrm{q} 1$ & 10 & Soft & Slovak Republic & $1996 q 2$ & $1998 \mathrm{q} 2$ & 9 & Hard \\
\hline Malaysia & $1983 q 1$ & $1984 q 2$ & 6 & Soft & Slovenia & $2004 q 1$ & $2009 q 2$ & 22 & Hard \\
\hline Malaysia & $1989 q 2$ & $1989 \mathrm{q} 4$ & 3 & Soft & South Africa & $2001 q 2$ & $2002 q 1$ & 4 & Soft \\
\hline Malaysia & $1992 \mathrm{q} 1$ & $1993 \mathrm{q} 1$ & 5 & Soft & South Africa & $2006 \mathrm{q} 1$ & $2009 q 1$ & 13 & Soft \\
\hline Malaysia & $1996 q 4$ & $1998 \mathrm{q} 3$ & 8 & Hard & Spain & $2006 \mathrm{q} 4$ & $2009 q 2$ & 11 & Hard \\
\hline Malaysia & $2013 q 1$ & $2013 q 2$ & 2 & Soft & Sri Lanka & $1977 q 1$ & $1979 q 4$ & 12 & Soft \\
\hline Malaysia & $2015 q 1$ & $2015 q 2$ & 2 & Soft & Sri Lanka & 1990q2 & $1991 \mathrm{q} 2$ & 5 & Soft \\
\hline Malta & $1975 q 1$ & $1975 \mathrm{q} 3$ & 3 & Soft & Sri Lanka & $1995 q 1$ & $1996 q 4$ & 8 & Soft \\
\hline Malta & $1980 \mathrm{q} 3$ & $1981 \mathrm{q} 2$ & 4 & Soft & Sri Lanka & $2012 q 1$ & $2012 q 2$ & 2 & Soft \\
\hline Malta & $1982 q 3$ & $1983 \mathrm{q} 2$ & 4 & Soft & Sri Lanka & $2014 q 4$ & $2015 q 4$ & 5 & Soft \\
\hline Malta & $2000 q 2$ & $2002 \mathrm{q} 1$ & 8 & Soft & Sweden & $2001 q 1$ & $2003 q 3$ & 11 & Soft \\
\hline Malta & $2008 \mathrm{q} 2$ & $2009 q 2$ & 5 & Soft & Switzerland & $1982 q 3$ & $1984 q 1$ & 7 & Soft \\
\hline Malta & $2012 q 1$ & $2012 q 1$ & 1 & Soft & Switzerland & $1989 q 2$ & $1991 q 3$ & 10 & Soft \\
\hline Mexico & $1976 \mathrm{q} 3$ & $1977 \mathrm{q} 3$ & 5 & Soft & Switzerland & $1999 \mathrm{q} 3$ & $2001 \mathrm{q} 1$ & 7 & Soft \\
\hline Mexico & $1987 \mathrm{q} 3$ & $1988 \mathrm{q} 2$ & 4 & Soft & Switzerland & $2006 \mathrm{q} 3$ & $2008 \mathrm{q} 3$ & 9 & Hard \\
\hline Mexico & $1989 q 1$ & $1995 \mathrm{q} 3$ & 27 & Hard & Switzerland & $2013 q 1$ & $2013 q 1$ & 1 & Soft \\
\hline Morocco & 1991q1 & $1992 \mathrm{q} 3$ & 7 & Soft & Taiwan & $1988 \mathrm{q} 1$ & $1990 \mathrm{q} 2$ & 10 & Soft \\
\hline Morocco & $1997 \mathrm{q} 4$ & $1999 \mathrm{q} 4$ & 9 & Soft & Taiwan & $2005 q 2$ & $2005 q 4$ & 3 & Soft \\
\hline Morocco & $2007 q 4$ & $2009 q 2$ & 7 & Soft & Taiwan & $2007 q 3$ & $2008 q 4$ & 6 & Soft \\
\hline Morocco & $2015 q 1$ & $2015 q 4$ & 4 & Soft & Thailand & $1976 \mathrm{q} 4$ & $1979 q 1$ & 10 & Soft \\
\hline Netherlands & $1996 \mathrm{q} 1$ & $1998 \mathrm{q} 1$ & 9 & Soft & Thailand & $1995 \mathrm{q} 4$ & $1999 \mathrm{q} 2$ & 15 & Hard \\
\hline New Zealand & $1986 q 4$ & $1990 \mathrm{q} 2$ & 15 & Soft & Thailand & $2010 q 2$ & $2010 q 3$ & 2 & Soft \\
\hline Norway & $1984 q 4$ & $1991 \mathrm{q} 2$ & 27 & Hard & Thailand & $2011 q 4$ & $2012 q 1$ & 2 & Soft \\
\hline Norway & $1997 \mathrm{q} 3$ & $1998 \mathrm{q} 4$ & 6 & Soft & Turkey & $1980 \mathrm{q} 4$ & $1982 q 2$ & 7 & Hard \\
\hline Norway & $2006 \mathrm{q} 2$ & $2006 q 4$ & 3 & Soft & Turkey & $1995 q 3$ & $1998 \mathrm{q} 3$ & 13 & Hard \\
\hline Panama & $1986 q 4$ & $1988 \mathrm{q} 1$ & 6 & Hard & Turkey & $2003 q 1$ & $2003 q 3$ & 3 & Soft \\
\hline Panama & 1991q1 & $1994 q 1$ & 13 & Soft & Turkey & $2004 q 2$ & $2007 q 1$ & 12 & Soft \\
\hline Panama & $1999 \mathrm{q} 2$ & $2002 q 2$ & 13 & Soft & Turkey & $2007 q 4$ & $2008 q 4$ & 5 & Soft \\
\hline Panama & $2007 q 4$ & $2009 q 1$ & 6 & Soft & Turkey & $2010 q 1$ & $2012 q 1$ & 9 & Soft \\
\hline Paraguay & $1988 \mathrm{q} 4$ & $1989 q 3$ & 4 & Soft & Turkey & $2014 q 1$ & $2015 q 1$ & 5 & Soft \\
\hline Paraguay & $1991 \mathrm{q} 3$ & $1994 \mathrm{q} 4$ & 14 & Hard & Ukraine & $1993 q 4$ & $1994 q 4$ & 5 & Soft \\
\hline Paraguay & $1997 \mathrm{q} 4$ & $1998 \mathrm{q} 3$ & 4 & Soft & Ukraine & $1997 q 3$ & $1998 \mathrm{q} 4$ & 6 & Hard \\
\hline Paraguay & $2001 \mathrm{q} 2$ & $2003 q 1$ & 8 & Soft & Ukraine & $1999 \mathrm{q} 3$ & $2004 q 3$ & 20 & Soft \\
\hline Paraguay & $2007 q 3$ & $2009 q 2$ & 8 & Soft & Ukraine & $2005 q 3$ & $2009 q 3$ & 17 & Hard \\
\hline Paraguay & $2010 q 2$ & $2010 q 4$ & 3 & Soft & Ukraine & $2014 q 1$ & $2015 q 1$ & 5 & Hard \\
\hline Paraguay & $2012 q 1$ & $2012 q 2$ & 2 & Soft & United Kingdom & $1989 q 2$ & $1991 \mathrm{q} 3$ & 10 & Soft \\
\hline Paraguay & $2015 q 2$ & $2015 q 4$ & 3 & Soft & United Kingdom & $2007 q 4$ & $2009 q 1$ & 6 & Hard \\
\hline Peru & $1982 \mathrm{q} 3$ & $1983 \mathrm{q} 2$ & 4 & Hard & United States & $1978 \mathrm{q} 3$ & $1980 \mathrm{q} 1$ & 7 & Soft \\
\hline Peru & $1989 q 1$ & $1992 \mathrm{q} 1$ & 13 & Soft & United States & $1988 \mathrm{q} 4$ & $1990 \mathrm{q} 4$ & 9 & Soft \\
\hline Peru & $1995 \mathrm{q} 3$ & $1999 q 1$ & 15 & Soft & United States & $2007 \mathrm{q} 2$ & $2009 q 1$ & 8 & Hard \\
\hline Peru & $2015 q 1$ & $2015 q 1$ & 1 & Soft & Uruguay & $1976 \mathrm{q} 1$ & $1976 \mathrm{q} 3$ & 3 & Soft \\
\hline Philippines & $1983 q 2$ & $1984 \mathrm{q} 3$ & 6 & Soft & Uruguay & $1978 q 2$ & $1981 q 2$ & 13 & Hard \\
\hline Philippines & $1993 \mathrm{q} 2$ & $1998 \mathrm{q} 3$ & 22 & Hard & Uruguay & $1982 q 4$ & $1983 q 1$ & 2 & Soft \\
\hline Poland & $1985 q 1$ & $1985 q 4$ & 4 & Soft & Uruguay & $1998 \mathrm{q} 1$ & $1999 q 3$ & 7 & Soft \\
\hline Poland & $1989 q 4$ & $1992 \mathrm{q} 1$ & 10 & Hard & Uruguay & $2002 q 1$ & $2003 q 3$ & 7 & Hard \\
\hline Poland & $2006 \mathrm{q} 3$ & $2009 q 2$ & 12 & Soft & Venezuela & $1976 q 1$ & $1977 q 2$ & 6 & Soft \\
\hline Portugal & $1997 \mathrm{q} 1$ & $2003 q 1$ & 25 & Soft & Venezuela & $1996 q 3$ & $1998 q 4$ & 10 & Soft \\
\hline \multirow[t]{2}{*}{ Portugal } & $2007 q 4$ & $2009 q 1$ & 6 & Hard & Venezuela & $2004 q 2$ & $2009 q 1$ & 20 & Hard \\
\hline & & & & & Average duration & & & 8.0 & \\
\hline
\end{tabular}

Notes: Credit booms identified using Gourinchas et al. (2001) and Barajas et al. (2009) criterion. For the identification of the outcome or kind of landing (soft or hard) we rely on Barajas et al. (2009) criterion. 
Table A2: Descriptive statistics for the spells and duration of credit booms

\begin{tabular}{lccccc}
\hline & \#Spells & Mean & St.Dev. & Min. & Max. \\
\hline All credit booms & 220 & 8.0 & 5.82 & 1 & 32 \\
Soft landing credit booms & 165 & 7.2 & 5.22 & 1 & 32 \\
Hard landing credit booms & 55 & 10.6 & 6.74 & 2 & 32 \\
\hline
\end{tabular}

Notes: This table reports the number of episodes/spells (\#Spells), the mean duration (Mean), the standard deviation (St.Dev.), the minimum (Min.) and the maximum (Max.) duration for credit booms. The data are quarterly and comprises 67 countries over the period 1975q12016q4. Credit booms are identified using the works of Gourinchas et al. (2001) and Barajas et al. (2009). A credit boom takes place when the deviation of the ratio of credit to GDP from its trend exceeds 1.5 times of its standard deviation or the (year-on-year) growth in the credit-GDP ratio exceeds 20 percent. Based on the identification strategy of Barajas et al. (2009), hard landings are defined as credit booms that are followed by a systemic banking crisis either immediately or within eight quarters of their final period. The others are considered soft landings. The episodes of systemic banking crises were obtained from Laeven and Valencia $(2008,2010,2012)$ and updated for the more recent years following their procedure.

Developed countries: Australia, Austria, Belgium, Bulgaria, Canada, Croatia, Cyprus, Czech Rep., Denmark, Estonia, Finland, France, Germany, Greece, Hungary, Iceland, Ireland, Italy, Japan, Latvia, Lithuania, Luxembourg, Malta, Netherlands, New Zealand, Norway, Poland, Portugal, Romania, Slovak Republic, Slovenia, Spain, Sweden, Switzerland, United Kingdom, United States.

Developing/Emerging countries: Argentina, Armenia, Bolivia, Brazil, Chile, Colombia, Costa Rica, Dominican Rep., Ecuador, El Salvador, India, Indonesia, Israel, Kenya, Korea Republic, Malaysia, Mexico, Morocco, Panama, Paraguay, Peru, Philippines, Russian Fed., South Africa, Sri Lanka, Taiwan, Thailand, Turkey, Ukraine, Uruguay, Venezuela.

\section{Table A3. Description of variables and respective sources}

\begin{tabular}{|c|c|c|}
\hline Variable & Description & Source \\
\hline CreditBoom & $\begin{array}{l}\text { Quarters in which the deviation of ratio of private credit to GDP from } \\
\text { its estimated trend is greater than } 1.5 \text { times its standard deviation or its } \\
\text { year-on-year growth rate exceeds } 20 \text { percent. }\end{array}$ & $\begin{array}{l}\text { Own calculations. Criterion based on } \\
\text { Gourinchas et al. (2001) and Barajas } \\
\text { et al. (2009). }\end{array}$ \\
\hline CapInflows & Total gross capital inflows as percentage of GDP (CapInflows). & $\begin{array}{l}\text { IMF Balance of Payments Statistics } \\
\text { and World Development Indicators. }\end{array}$ \\
\hline CredDeposit & $\begin{array}{l}\text { Ratio of private credit to bank deposits (Credit/Deposits). Deposits are } \\
\text { measured as the sum of demand and time deposits. }\end{array}$ & $\begin{array}{l}\text { IMF-International Financial Statistics } \\
\text { (IFS), lines } 24 \text { and } 25 .\end{array}$ \\
\hline RealGDPgr & Year-over-year GDP growth rate. & Datastream and national sources \\
\hline Openness & Exports plus imports over GDP. & IMF - IFS \\
\hline ExchRateFlex & $\begin{array}{l}\text { Exchange rate flexibility. Set by the coarse classification of the } \\
\text { exchange rate regime. The coarse index varies between } 1 \text { and } 6 \text { : higher } \\
\text { values indicate a more flexible exchange rate arrangement. }\end{array}$ & $\begin{array}{l}\text { Reinhart and Rogoff (2004), and } \\
\text { Ilzetzky, Reinhart and Rogoff (2009). }\end{array}$ \\
\hline CBrate & Central Bank base rate. & IMF - IFS \\
\hline CBindep & Cukierman-Webb-Neyapti index. & Garriga (2016) \\
\hline GovStab & $\begin{array}{l}\text { Government stability index which measures the government's ability to } \\
\text { carry out its programme and to stay in office. }\end{array}$ & International Country Risk Guide \\
\hline Volatility & VXO volatility index of Chicago Board Options Exchange S\&P 100. & Federal Reserve Bank of St. Louis. \\
\hline Developed & Dummy equal to 1 for developed countries; 0 , otherwise. & United Nations \\
\hline
\end{tabular}

Table A4. Descriptive statistics for the variables

\begin{tabular}{|c|c|c|c|c|c|}
\hline Variable & Obs. & Mean & Std. Dev. & Min. & Max. \\
\hline CapInflows & 1360 & 0.24 & 1.28 & 1.86 & 19.05 \\
\hline CredDeposit & 1740 & 6.53 & 8.83 & 0.06 & 105.88 \\
\hline RealGDPgr & 1715 & 3.93 & 3.88 & -20.76 & 18.29 \\
\hline Openness & 1290 & 0.79 & 0.45 & 0.13 & 3.58 \\
\hline ExchRateFlex & 1773 & 2.54 & 1.32 & 1.00 & 6.00 \\
\hline CBrate & 1516 & 11.28 & 13.51 & 0.00 & 149.00 \\
\hline CBindep & 1697 & 0.55 & 0.25 & 0.10 & 0.90 \\
\hline GovStab & 1546 & 7.82 & 1.96 & 1.00 & 11.67 \\
\hline Volatility & 1533 & 22.03 & 9.04 & 9.19 & 54.16 \\
\hline Developed & 1781 & 0.46 & 0.50 & 0 & 1 \\
\hline
\end{tabular}
and maximum (Max.) for the periods of credit booms (the ones considered in the estimations). 